\title{
De novo Synthesis of a D-Galacturonic Acid Thioglycoside as Key to the Total Synthesis of a Glycosphingolipid from Sphingomonas yanoikuyae
}

Pierre Stallforth, Alexander Adibekian and Peter H. Seeberger*

Laboratory for Organic Chemistry,

Swiss Federal Institute of Technology (ETH) Zürich,

ETH-Hönggerberg, HCI F 315,

Wolfgang-Pauli-Str. 10,

CH-8093 Zürich, Switzerland

E-mail: seeberger@org.chem.ethz.ch

SUPPORTING INFORMATION - Part II

NMR Spectra 


\section{Table of Contents}

${ }^{1} \mathrm{H}$ and ${ }^{13} \mathrm{C}$ spectra of compound 2

S2-3

${ }^{1} \mathrm{H}$ and ${ }^{13} \mathrm{C}$ spectra of compound 3a

S2-5

${ }^{1} \mathrm{H}$ and ${ }^{13} \mathrm{C}$ spectra of compound $\mathbf{3 b}$

S2-7

${ }^{1} \mathrm{H}$ and ${ }^{13} \mathrm{C}$ spectra of compound $\mathbf{4 a}$

S2-9

${ }^{1} \mathrm{H}$ and ${ }^{13} \mathrm{C}$ spectra of compound $\mathbf{4 b}$

${ }^{1} \mathrm{H},{ }^{13} \mathrm{C}$ and ${ }^{1} \mathrm{H}$ NOE spectra of compound $\mathbf{5 a}$

${ }^{1} \mathrm{H}$ and ${ }^{13} \mathrm{C}$ spectra of compound $\mathbf{5 b}$

${ }^{1} \mathrm{H},{ }^{13} \mathrm{C}$ and ${ }^{31} \mathrm{P}$ spectra of compound $\mathbf{6}$

${ }^{1} \mathrm{H}$ and ${ }^{13} \mathrm{C}$ spectra of compound $\mathbf{7}$

${ }^{1} \mathrm{H}$ and ${ }^{13} \mathrm{C}$ spectra of compound $\mathbf{8}$

${ }^{1} \mathrm{H}$ and ${ }^{13} \mathrm{C}$ spectra of compound $\mathbf{9}$

${ }^{1} \mathrm{H}$ and ${ }^{13} \mathrm{C}$ spectra of compound $\mathbf{1 0}$

${ }^{1} \mathrm{H}$ and ${ }^{13} \mathrm{C}$ spectra of compound $\mathbf{H}$

S2-31

${ }^{1} \mathrm{H}$ and ${ }^{13} \mathrm{C}$ spectra of compound $\mathbf{F}$

S2-33

${ }^{1} \mathrm{H}$ and ${ }^{13} \mathrm{C}$ spectra of compound 11a

${ }^{1} \mathrm{H}$ and ${ }^{13} \mathrm{C}$ spectra of compound $\mathbf{1 2}$

${ }^{1} \mathrm{H}$ and ${ }^{13} \mathrm{C}$ spectra of compound $\mathbf{1 3}$ 


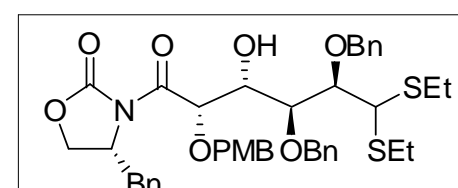

$\mathrm{CDCl}_{3}, 300 \mathrm{MHz}$

Bn

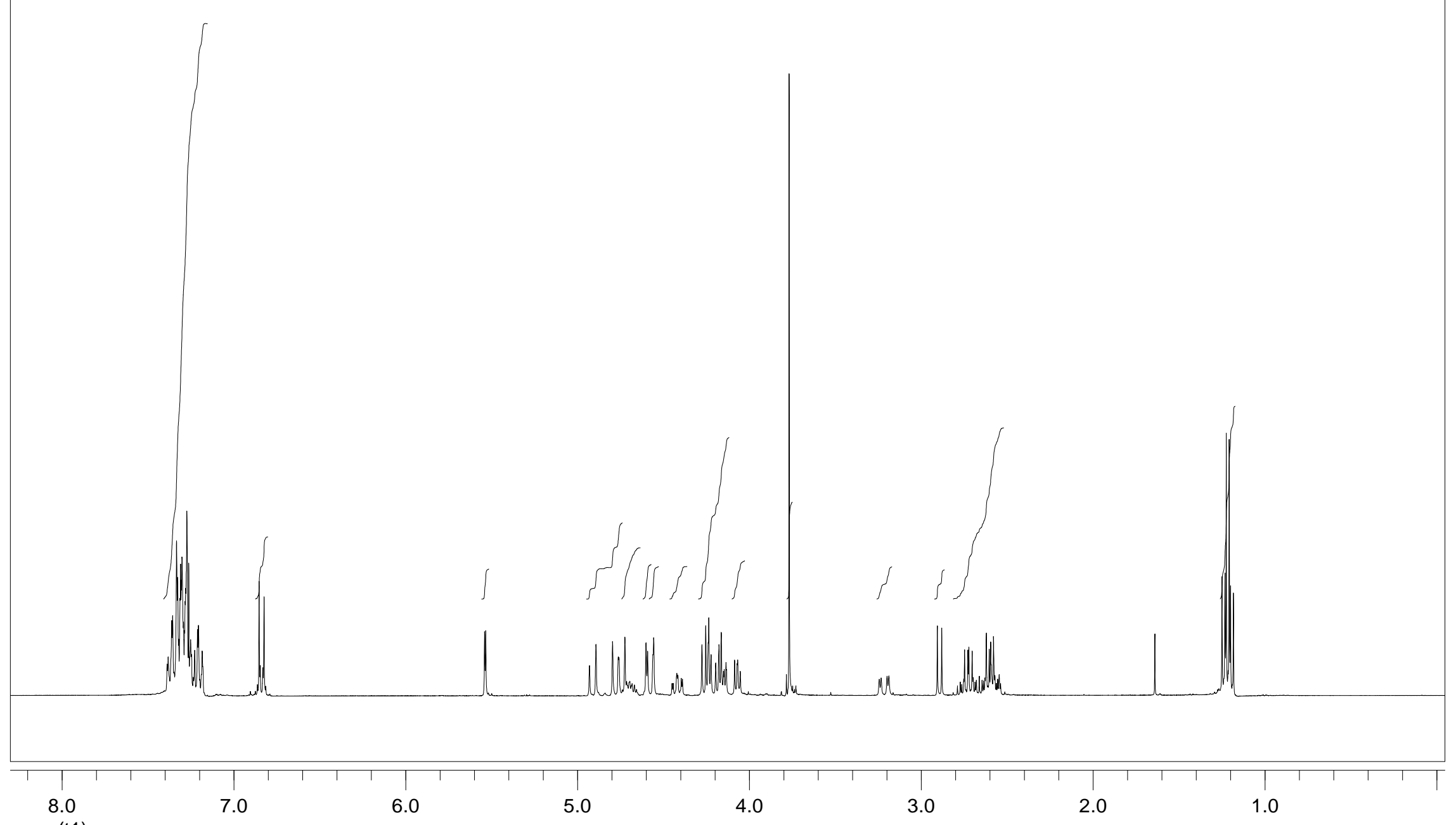

ppm (t1) 


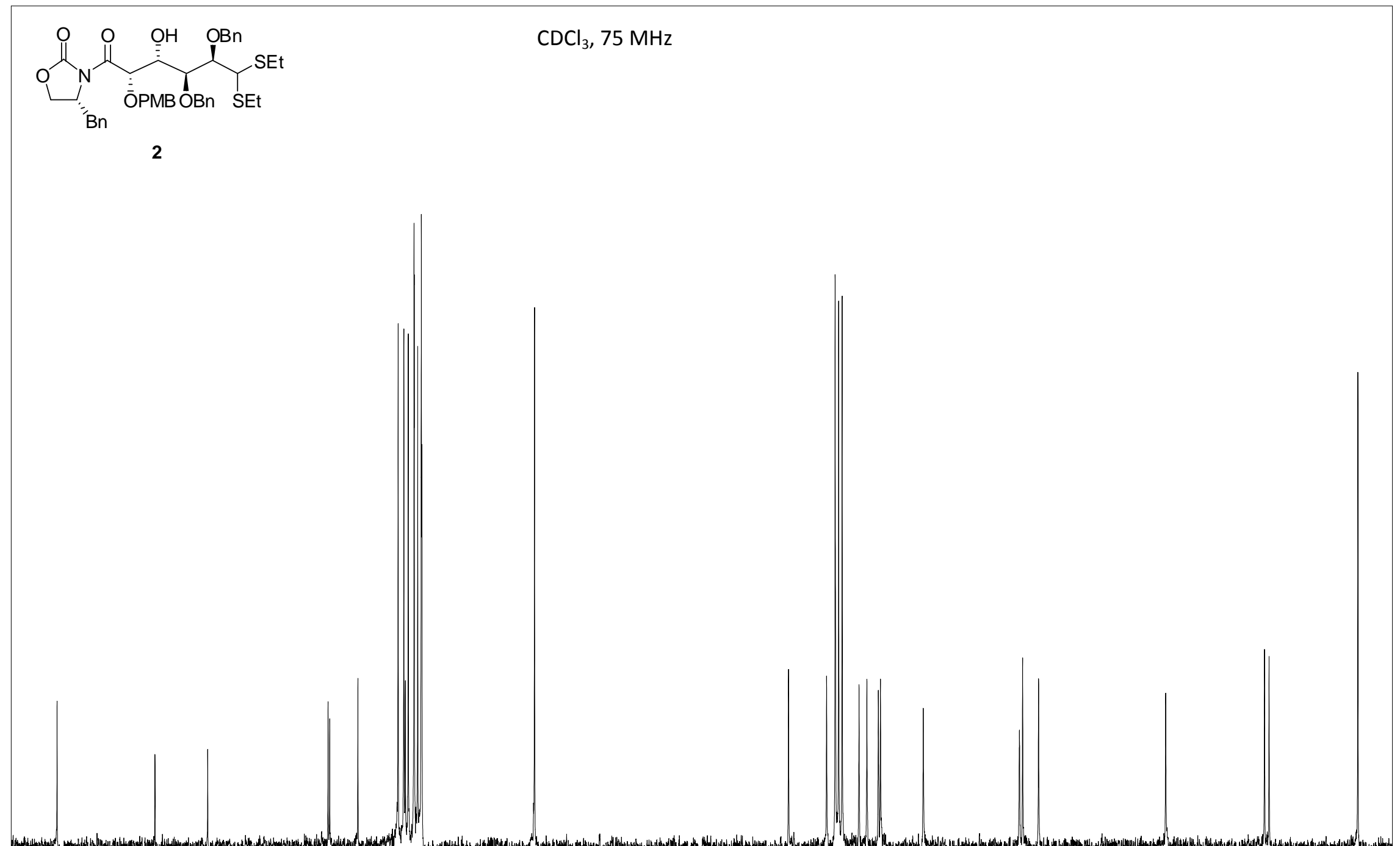

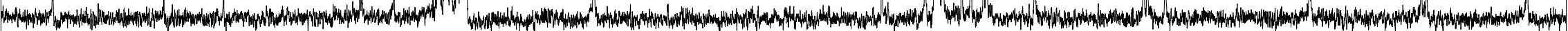

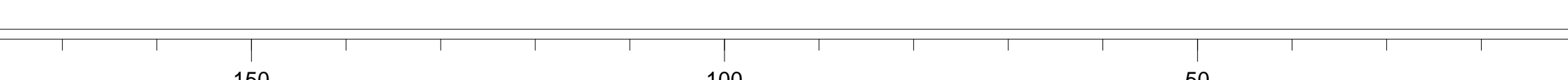

ppm (f1)

150

100 


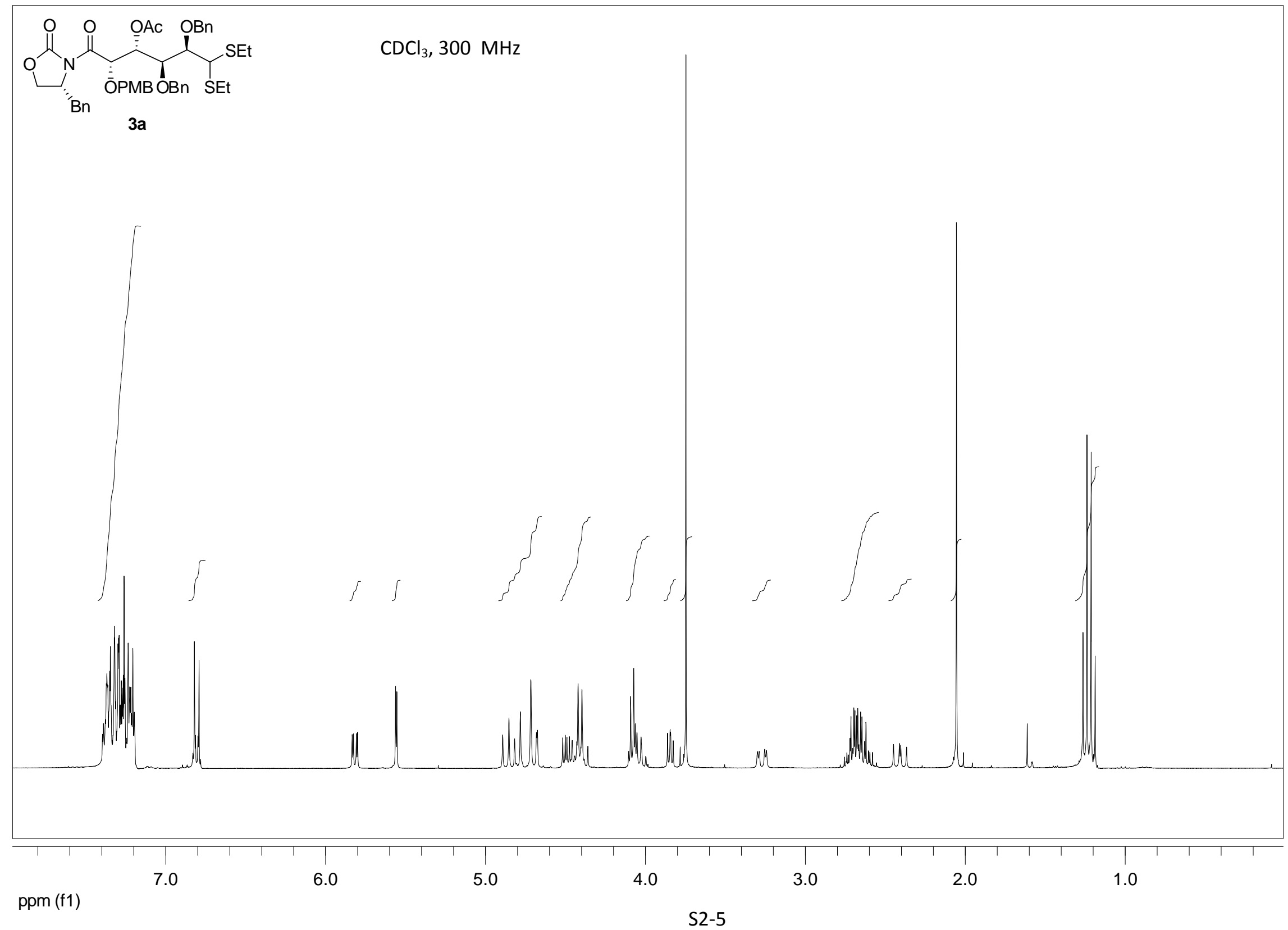




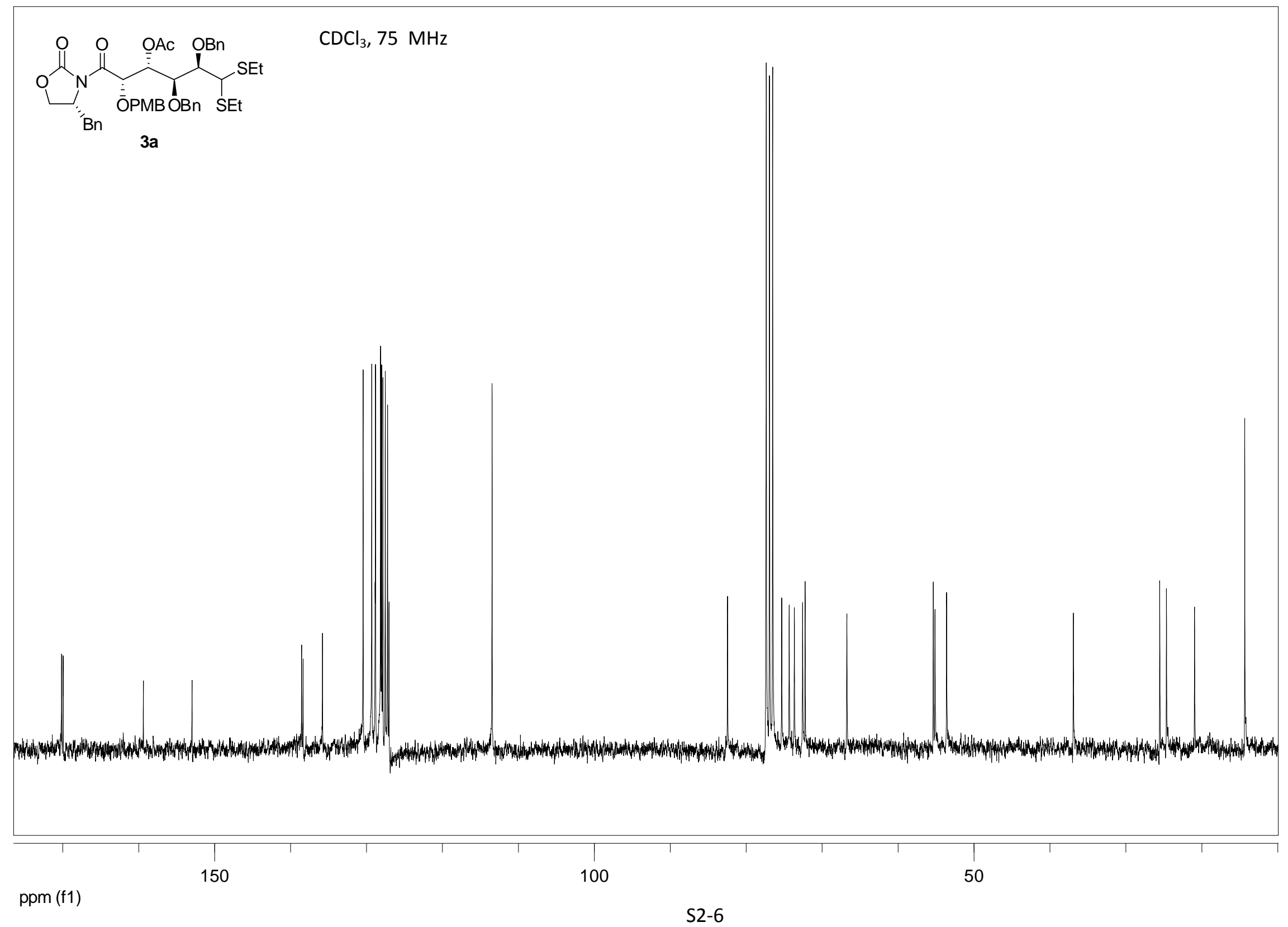




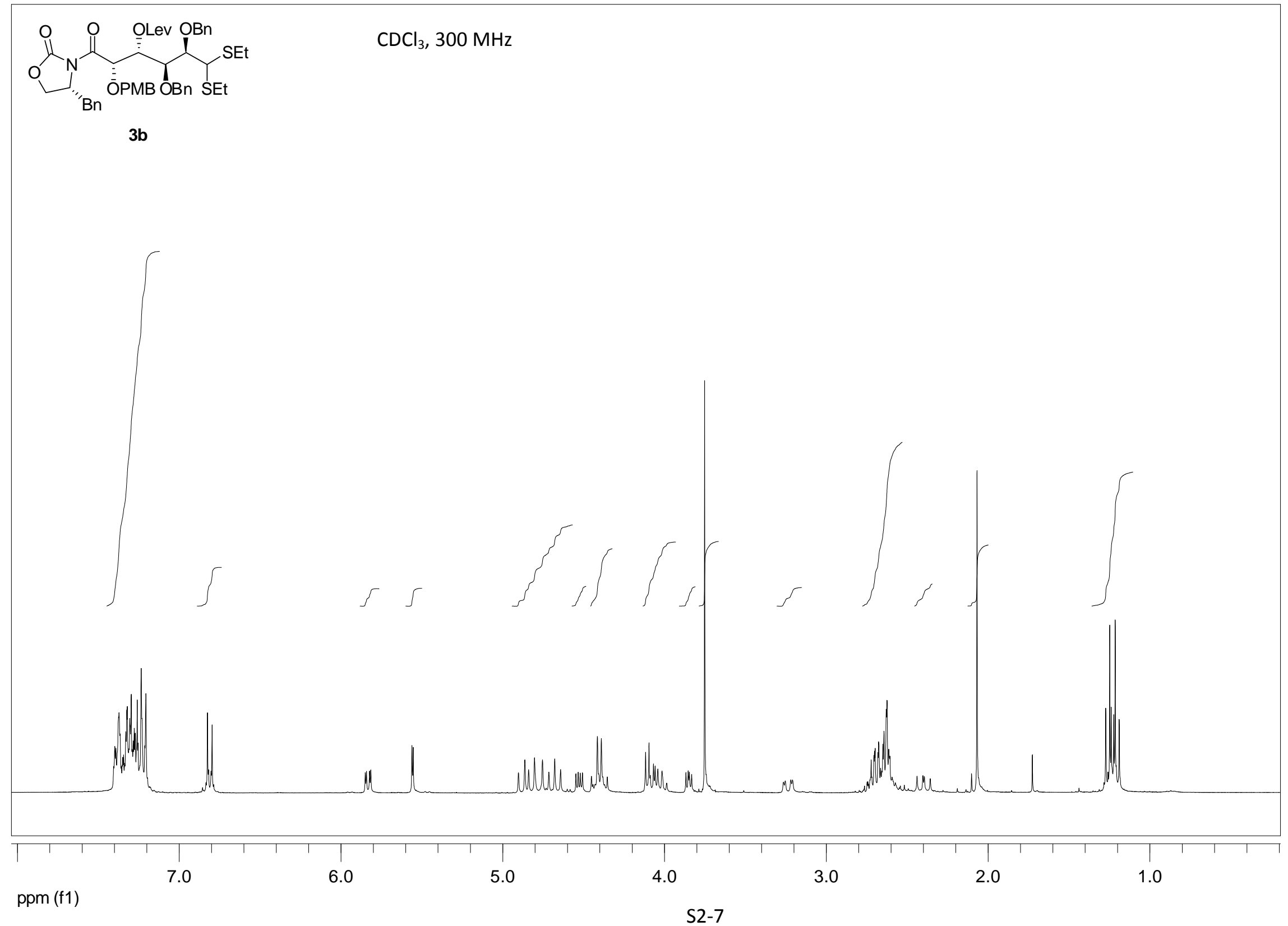




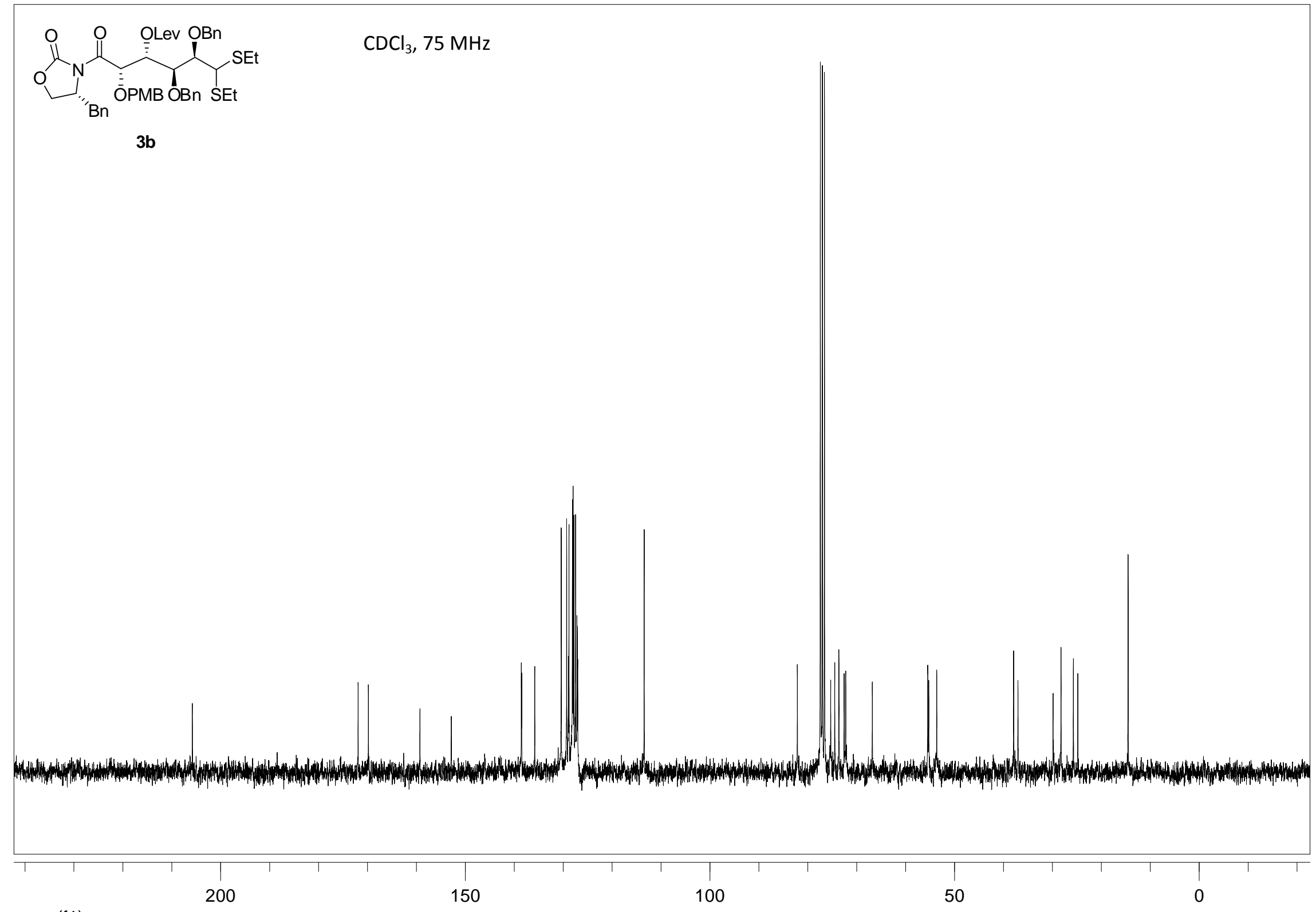

ppm (f1) 


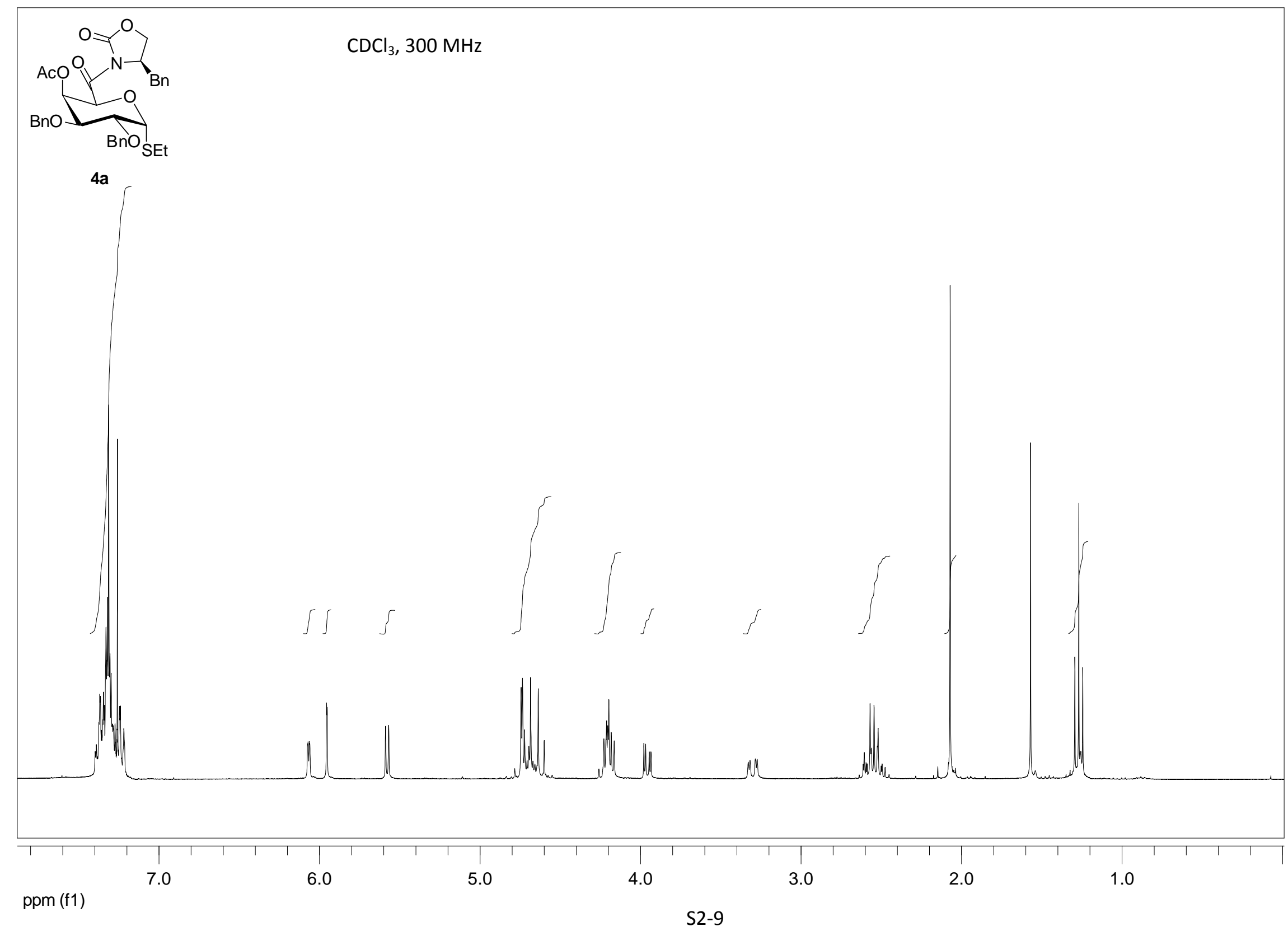




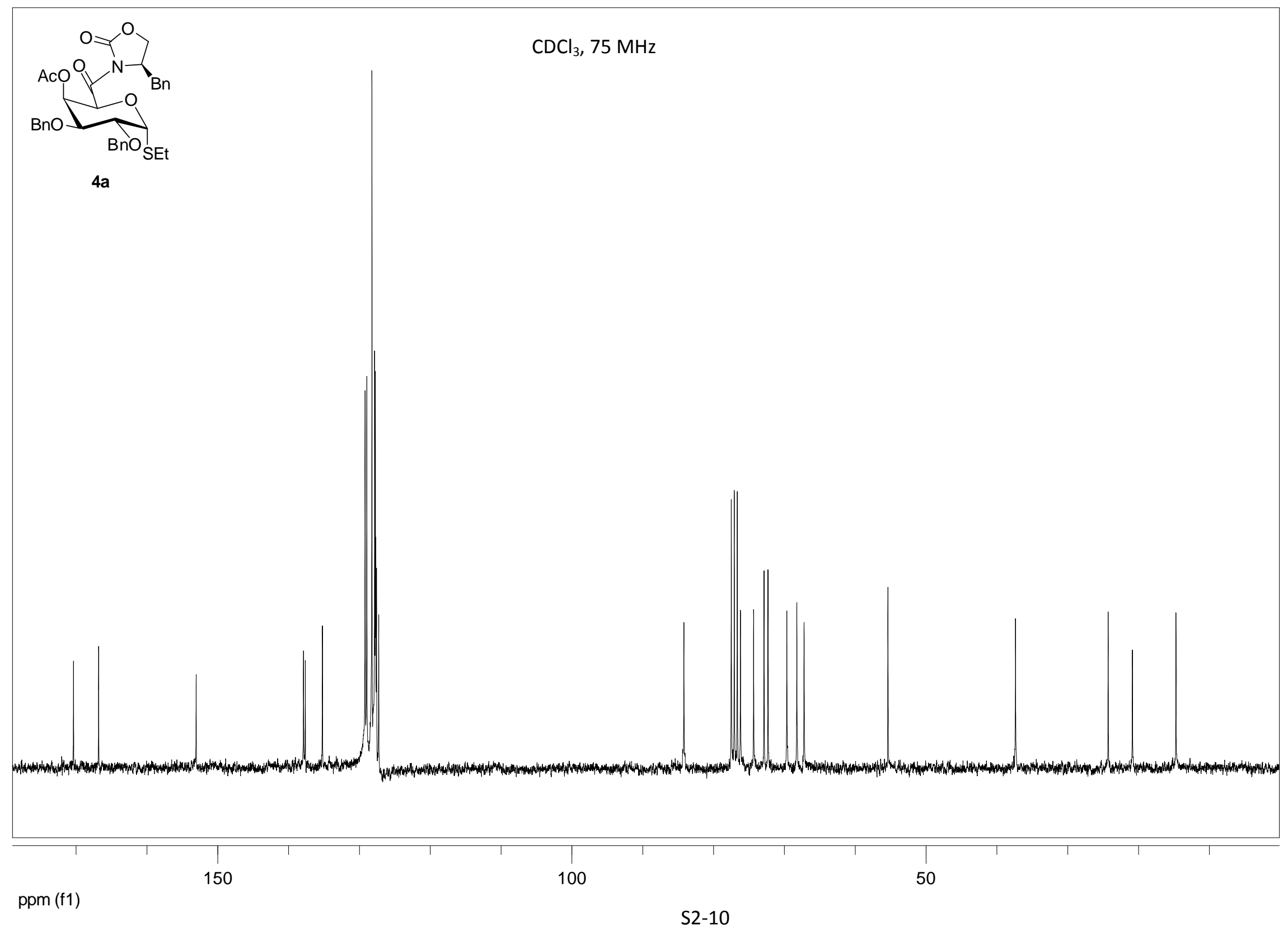




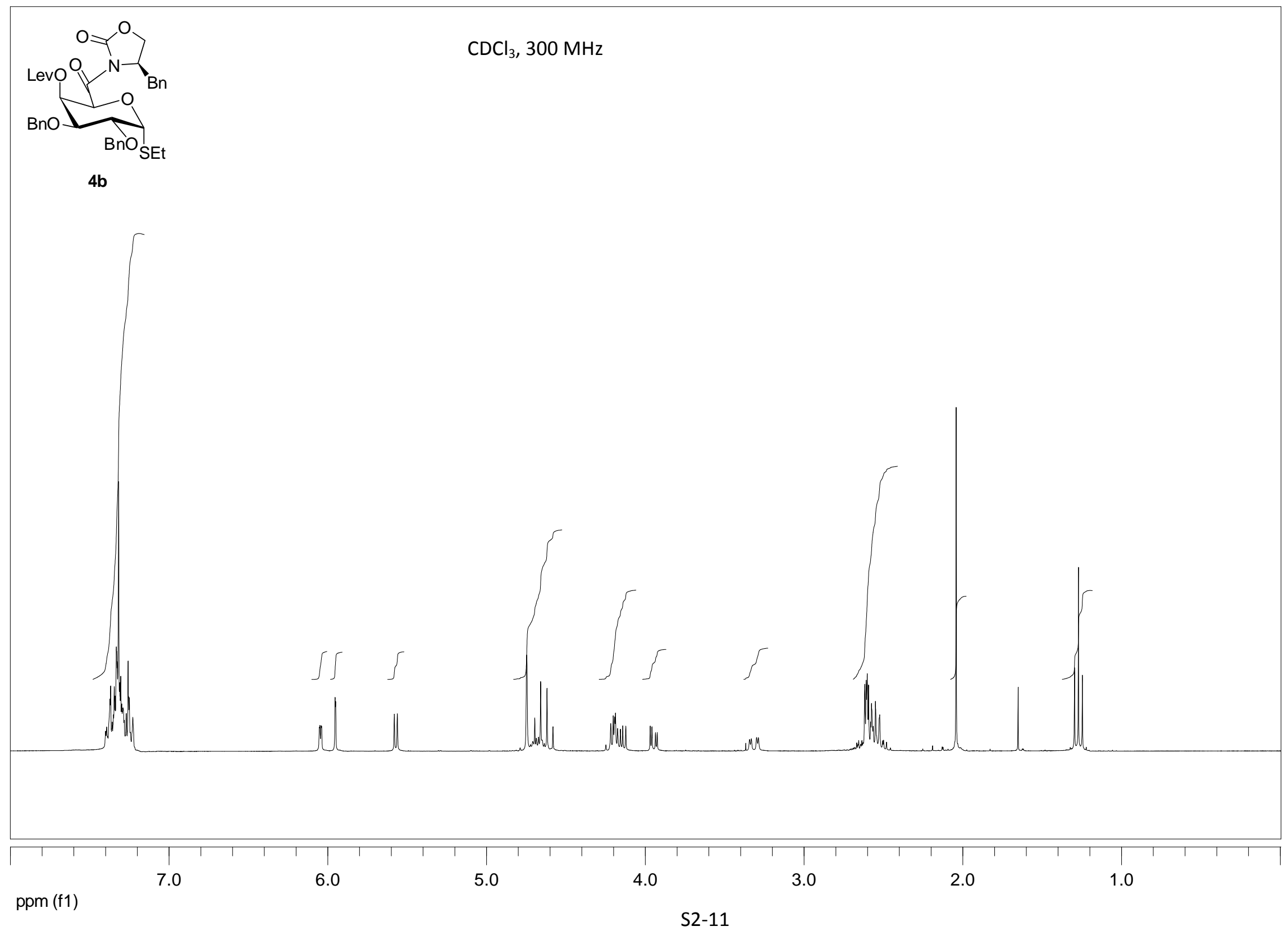




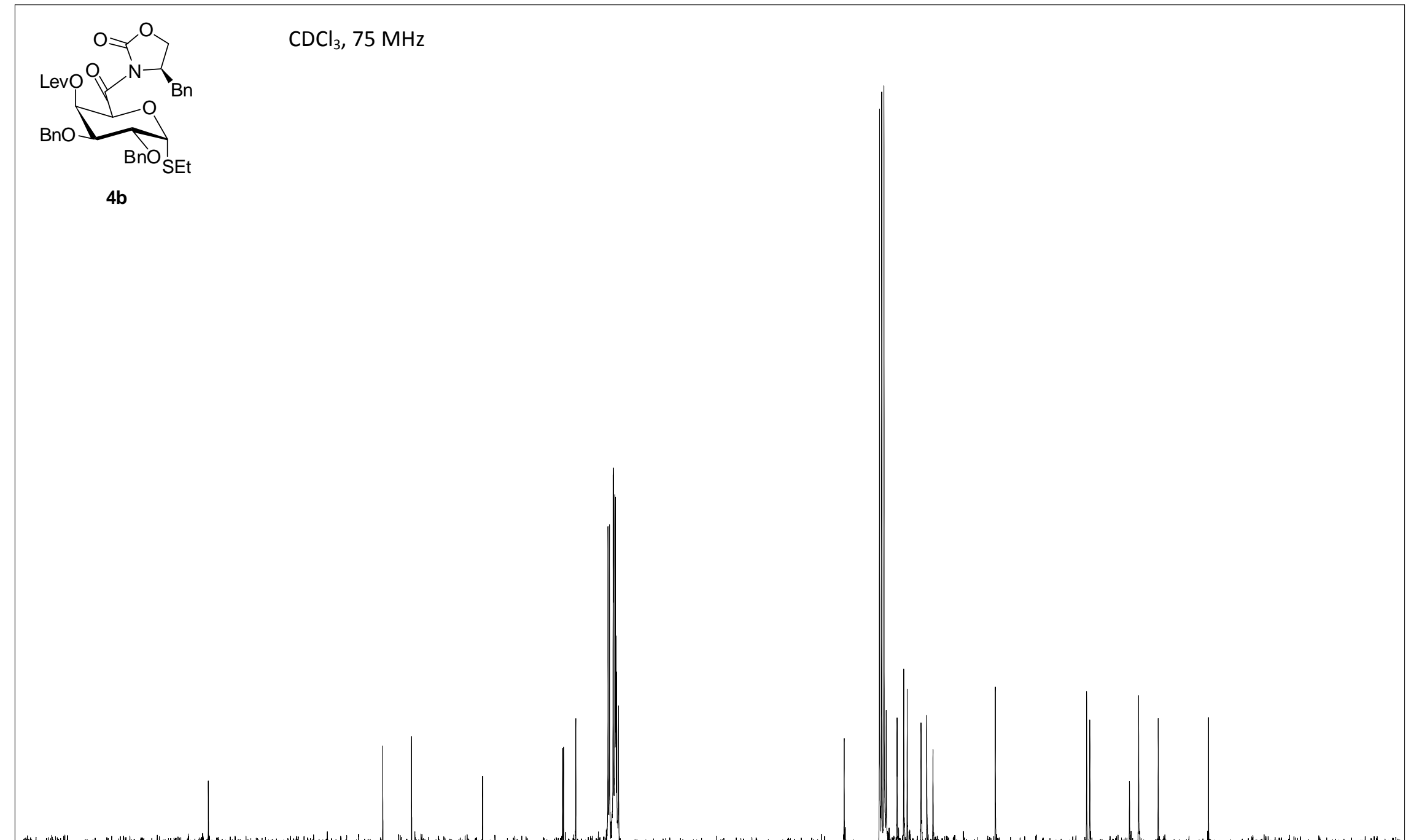

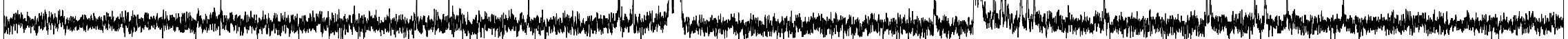

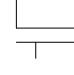

ppm (f1)

200

150

100

50

0

S2-12 


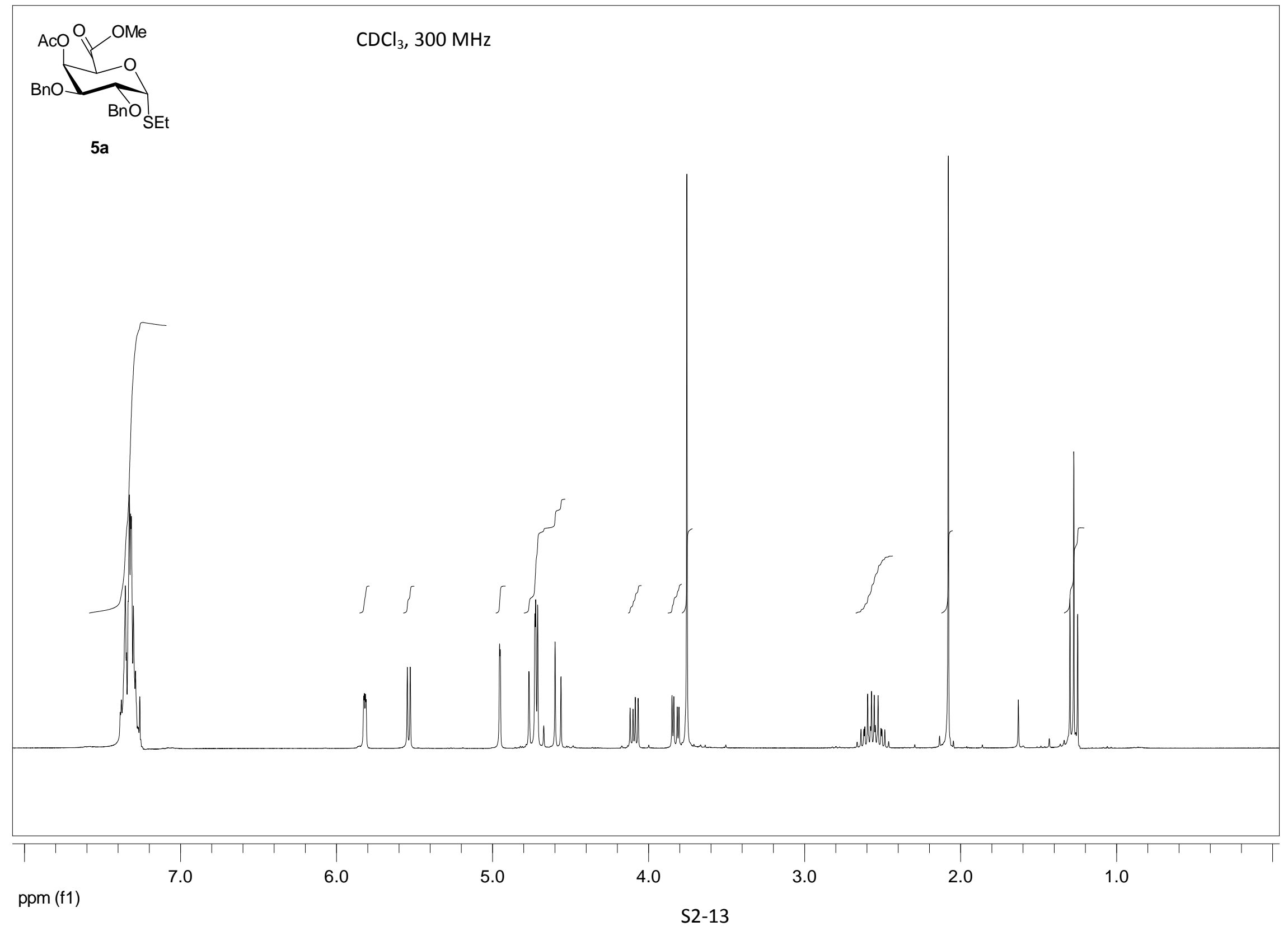




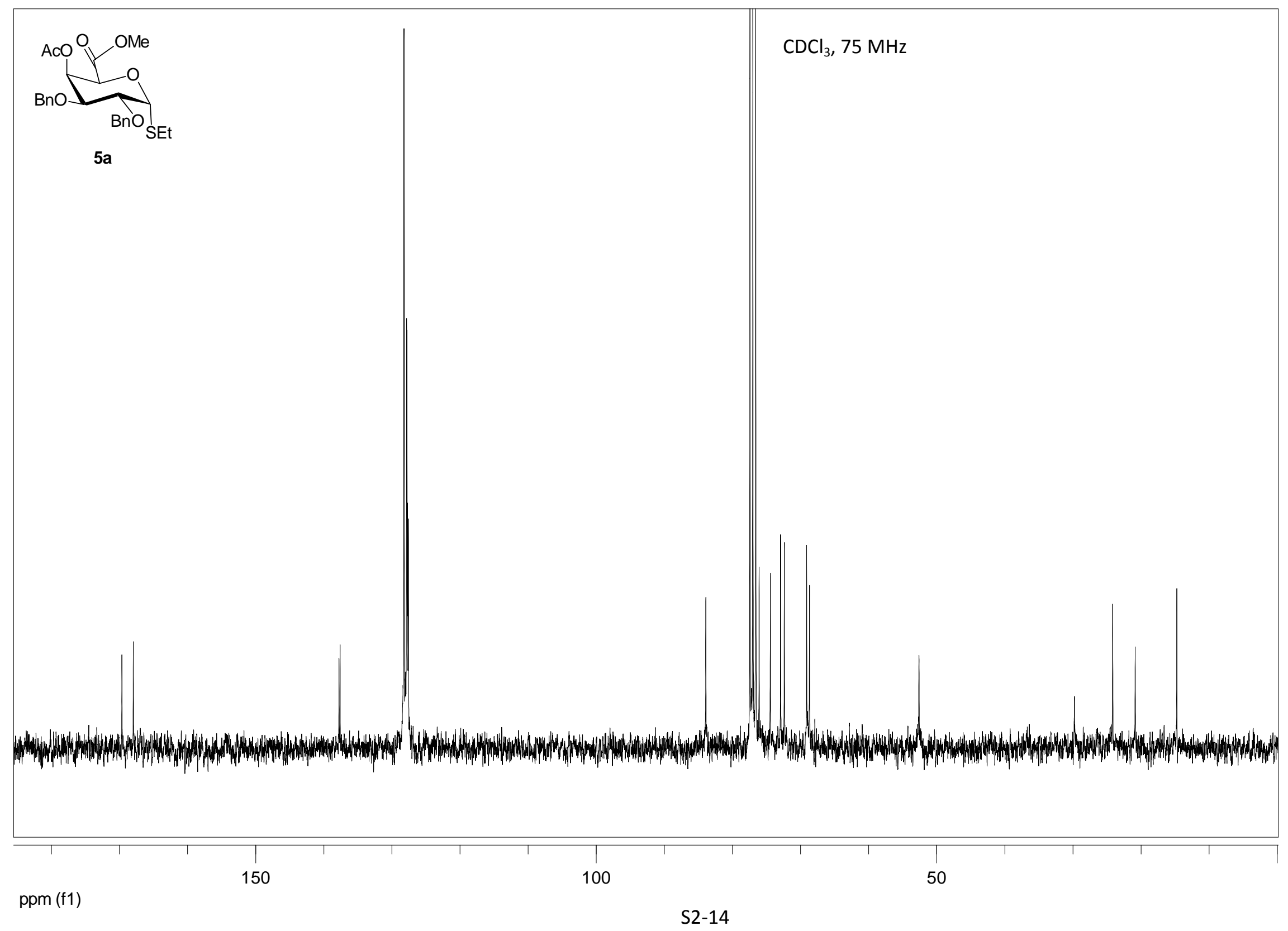




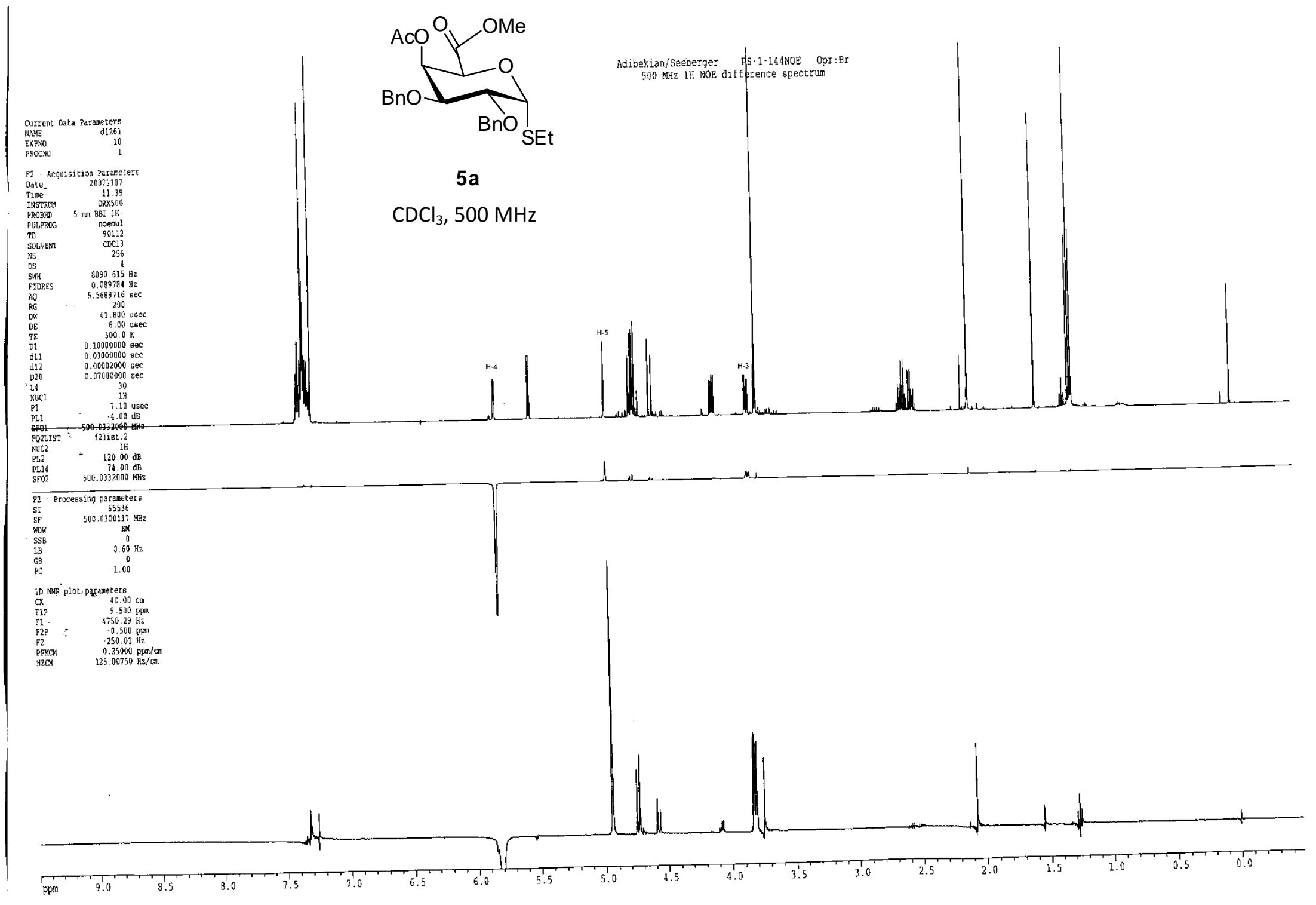

S2-15 


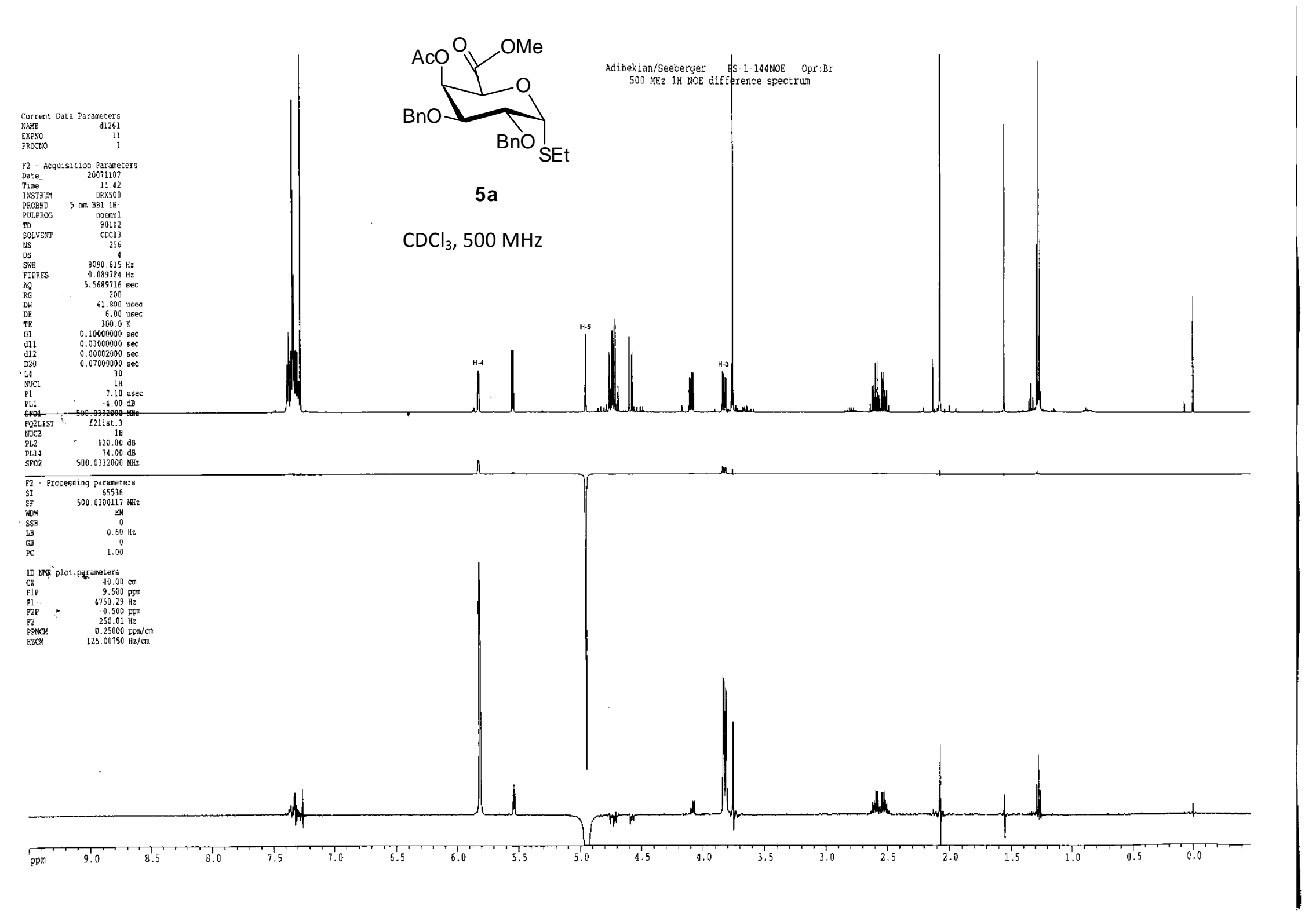

S2-16 


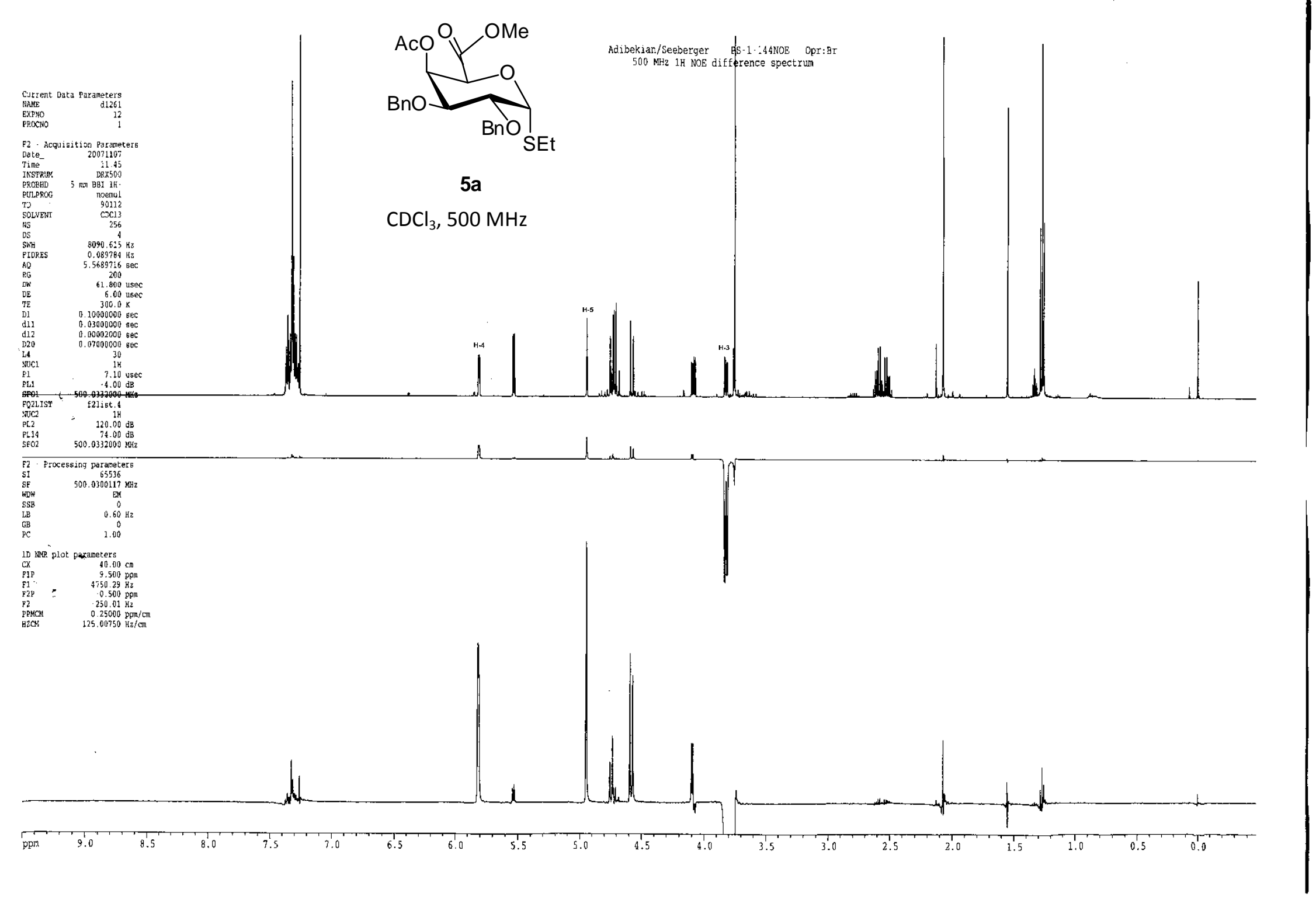

S2-17 


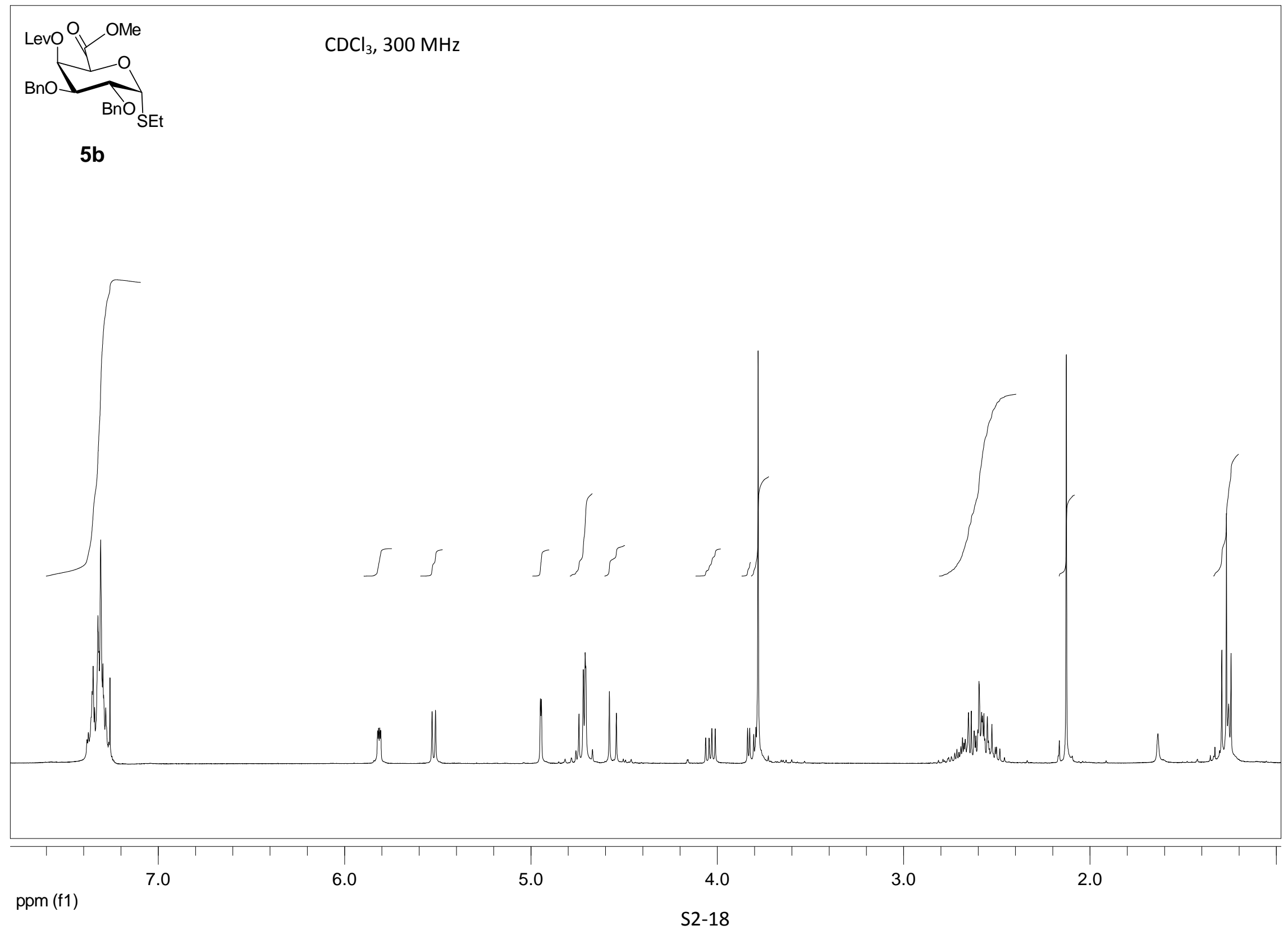




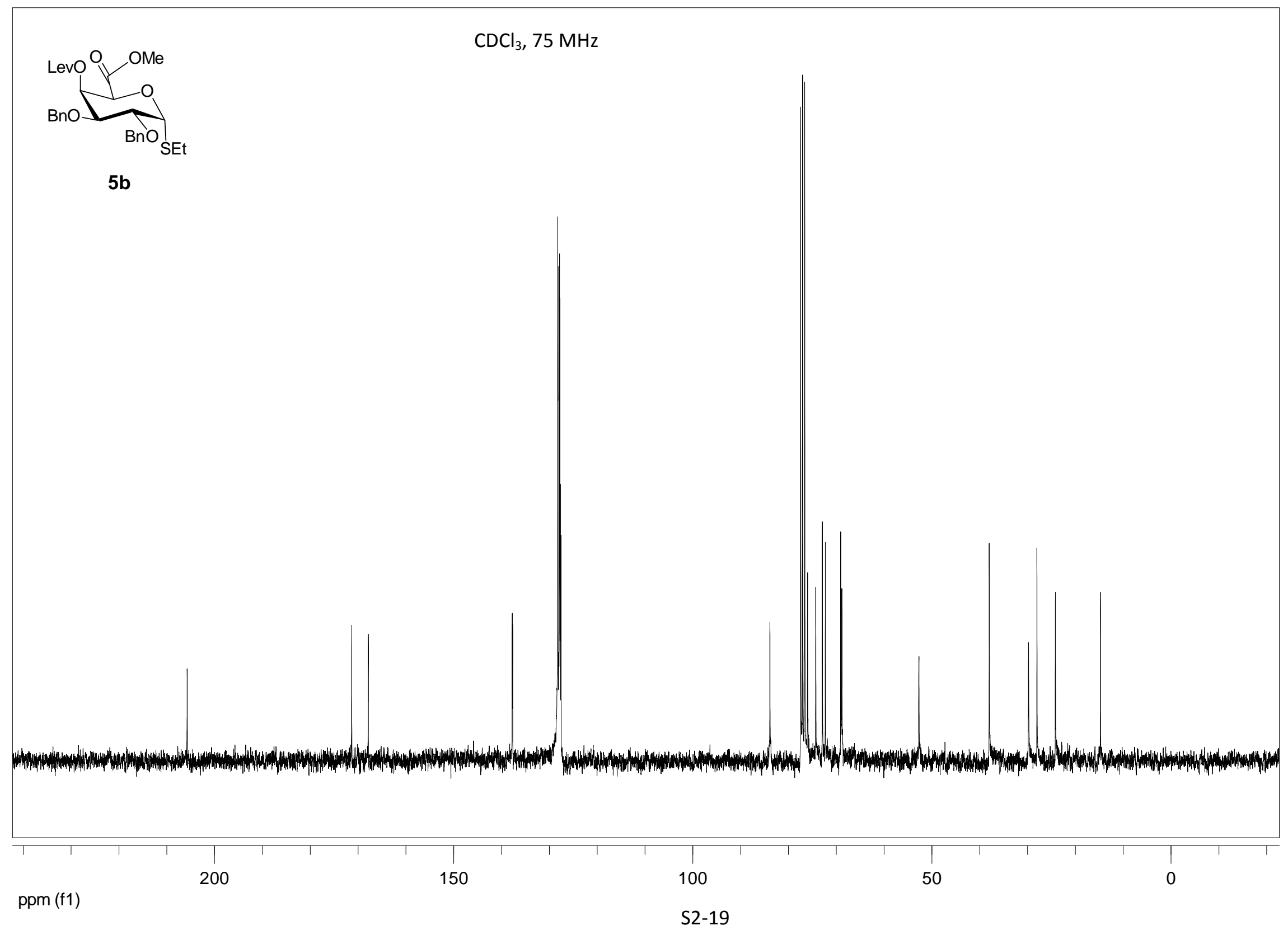




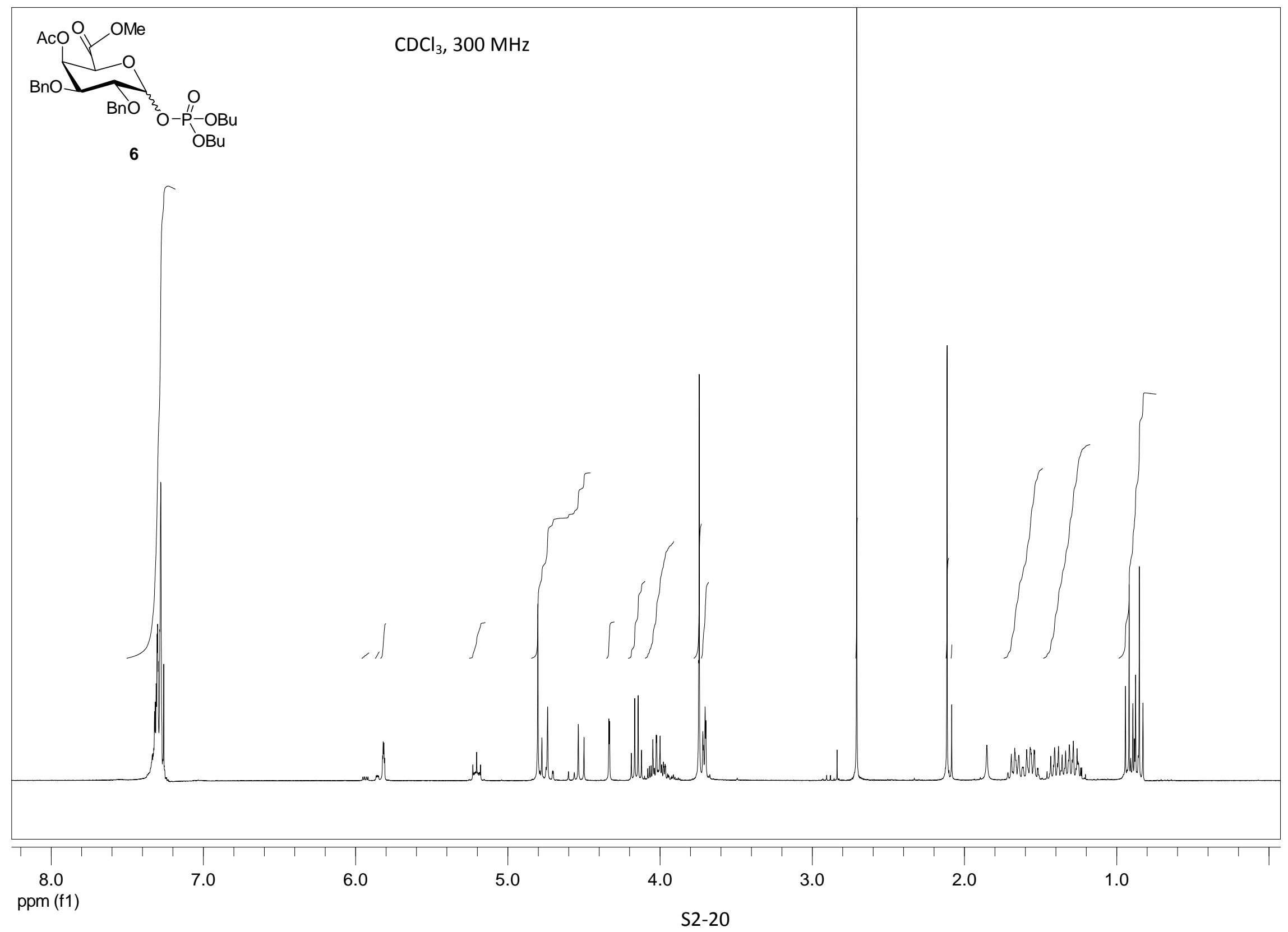



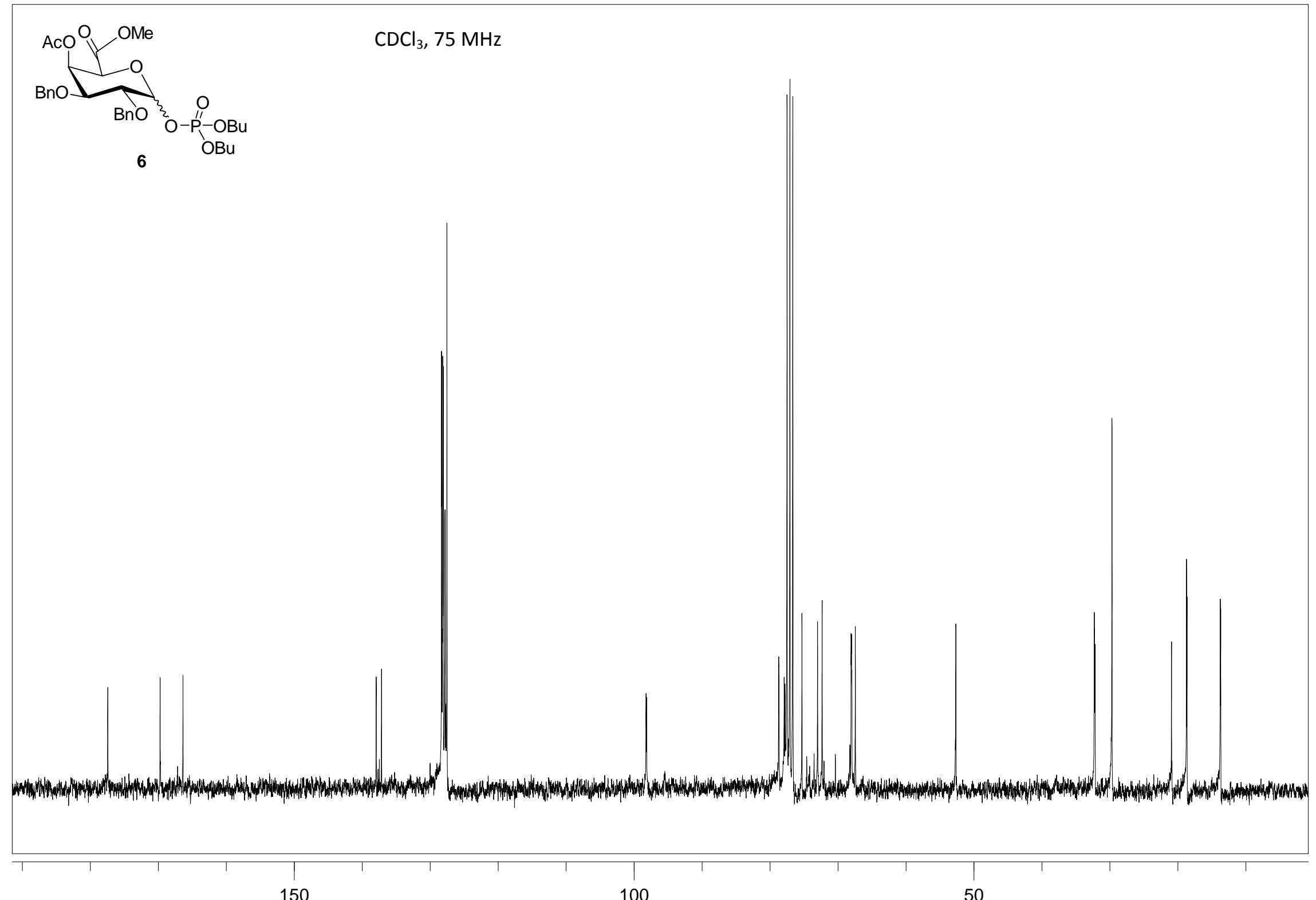

ppm (f1)

100

50

S2-21 


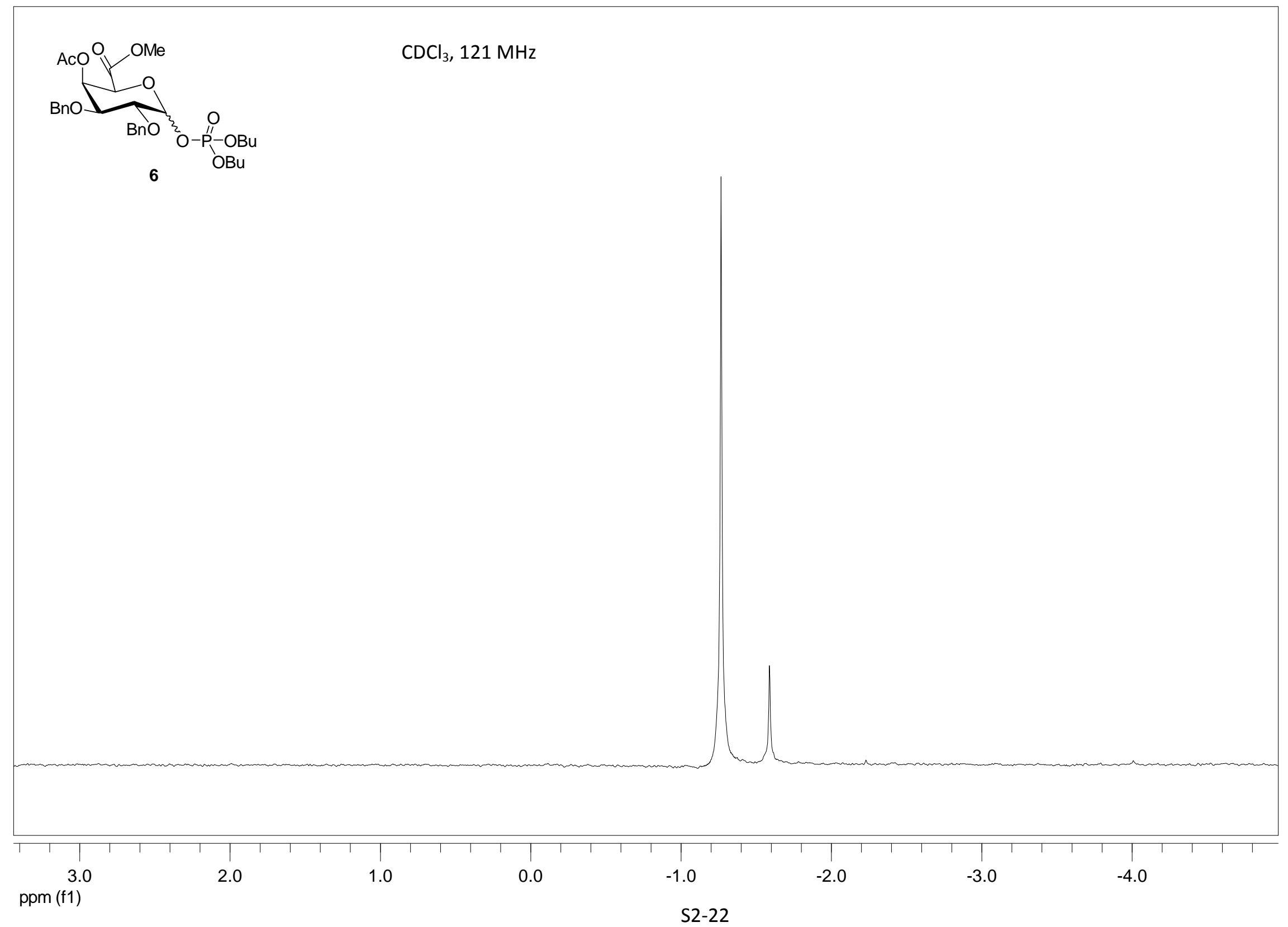




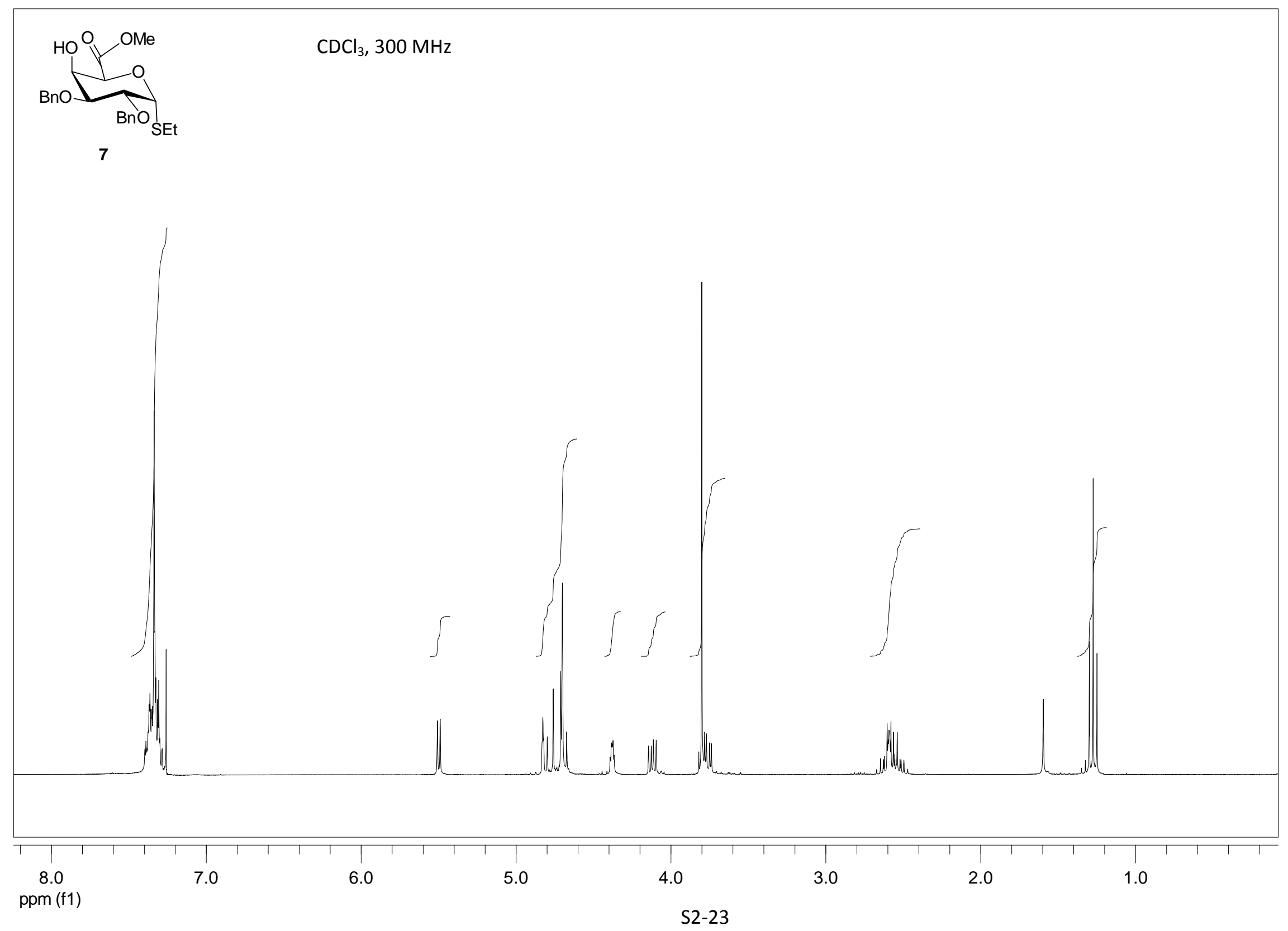




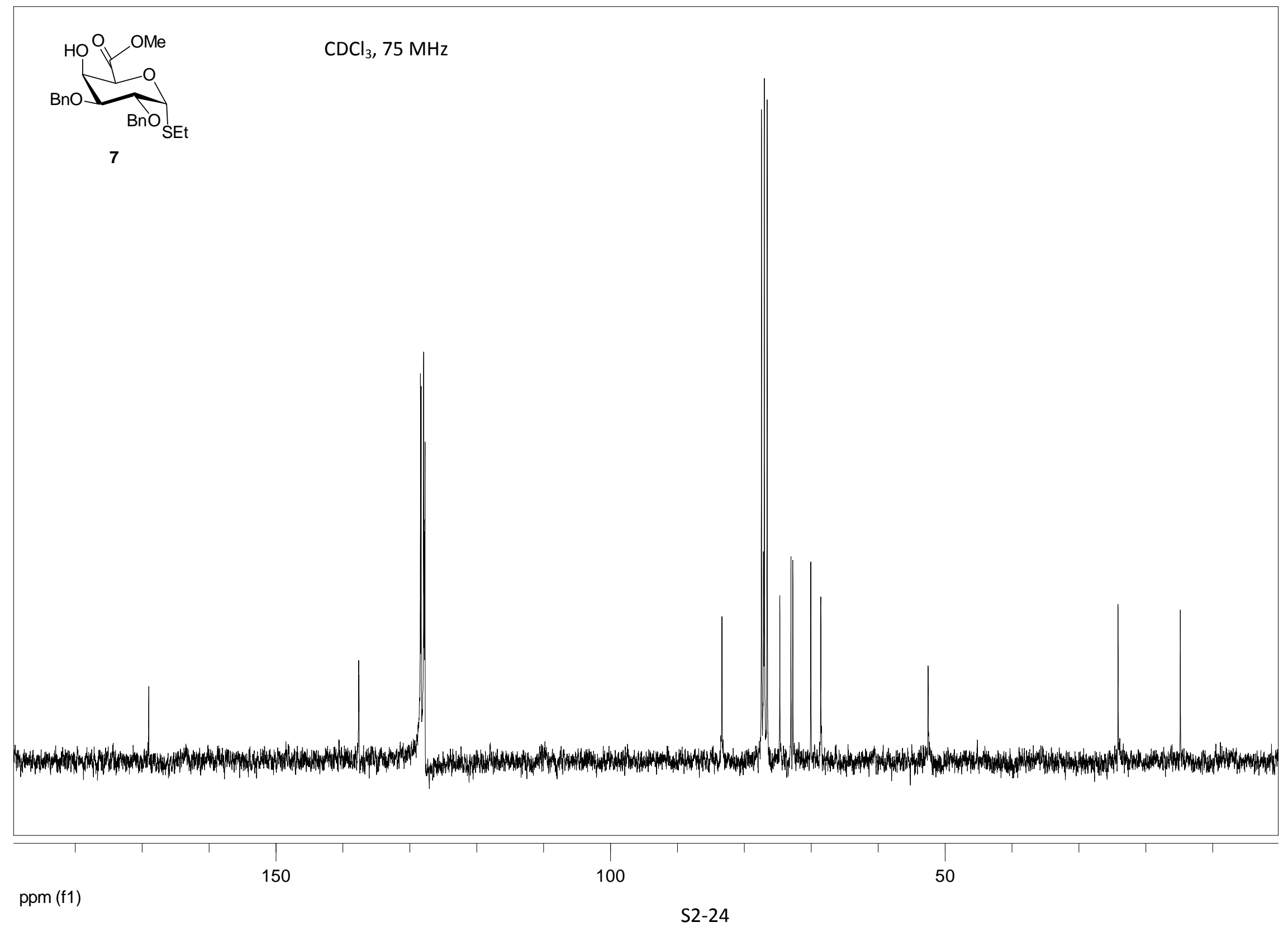




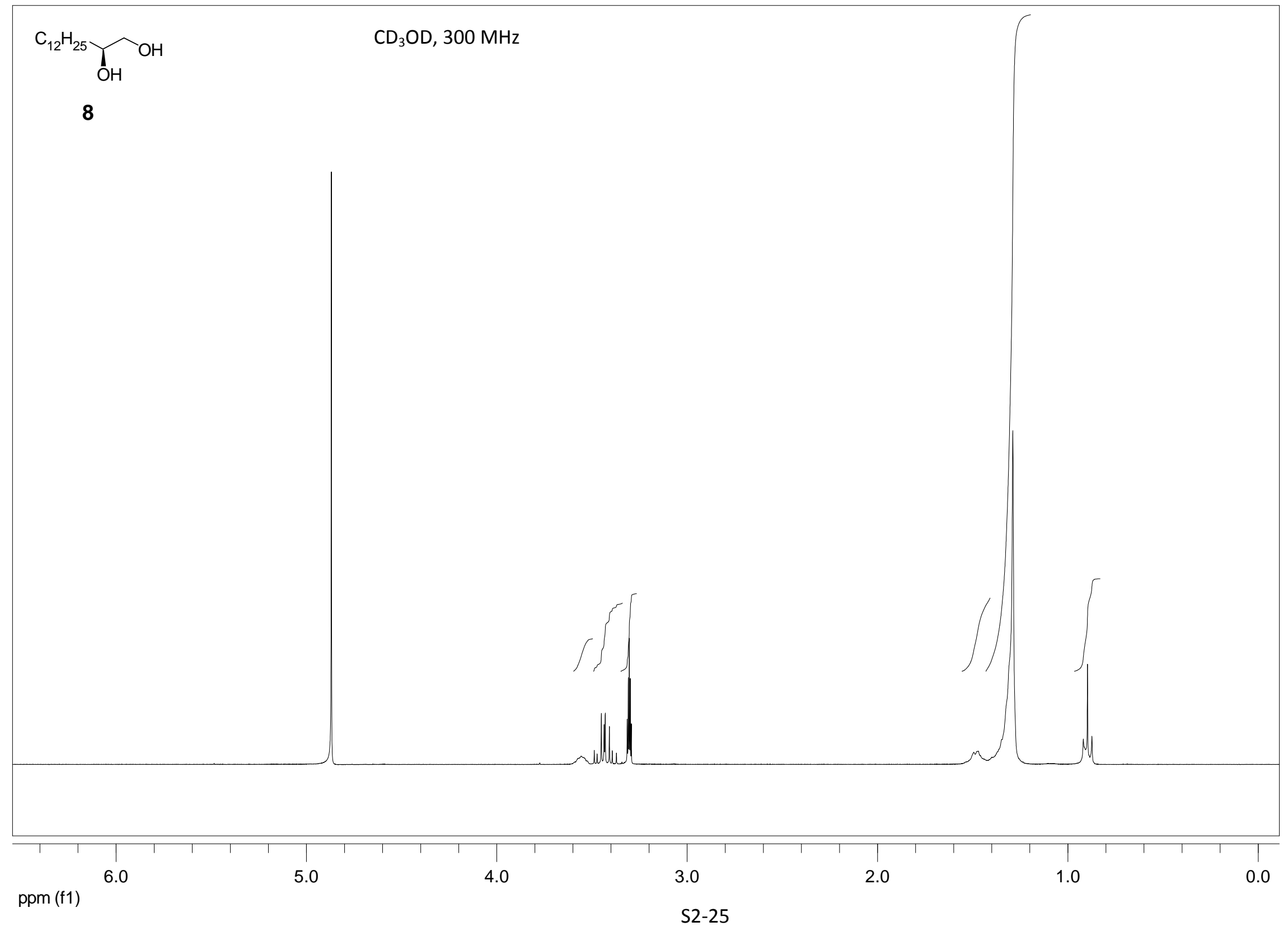




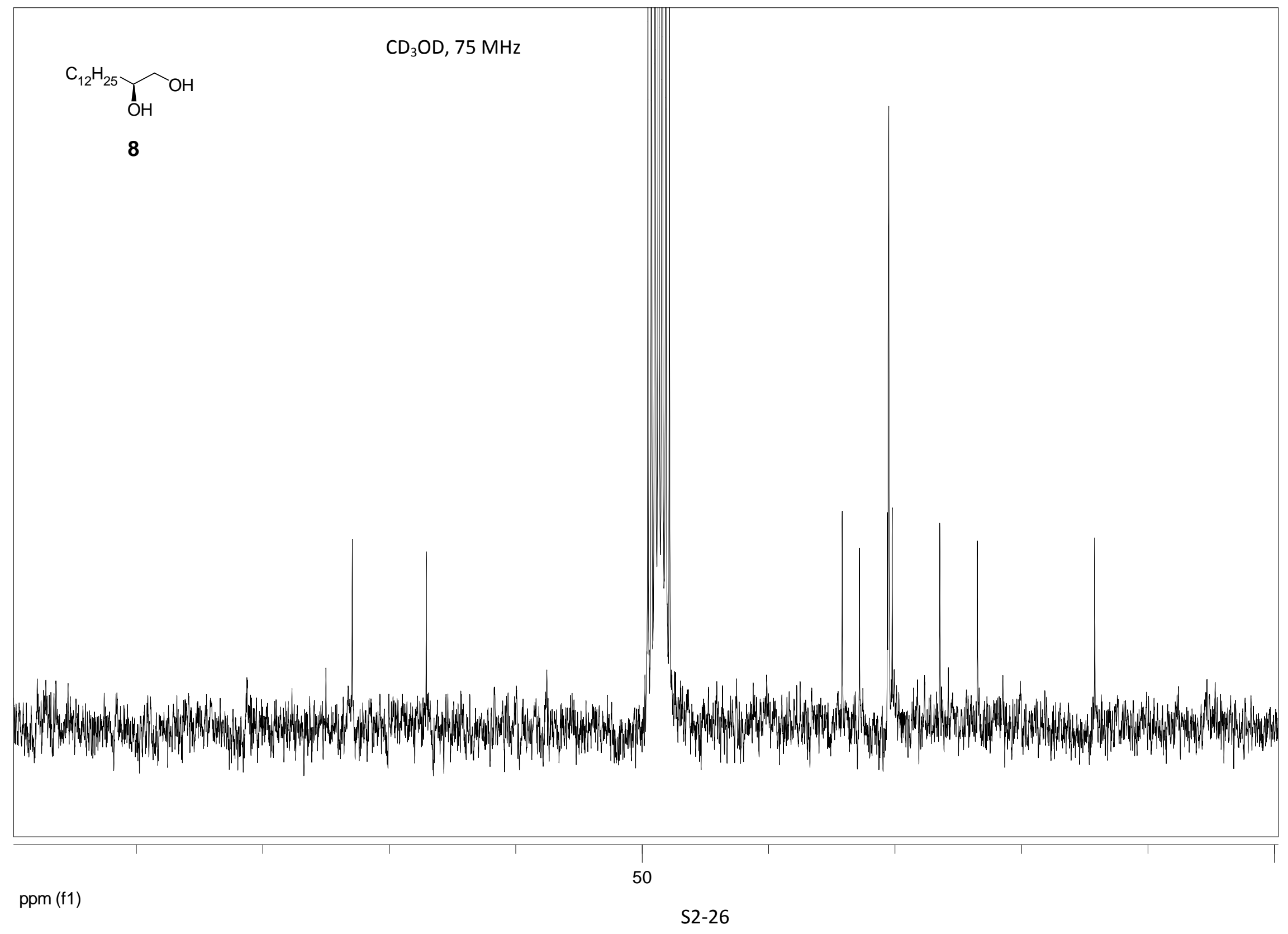




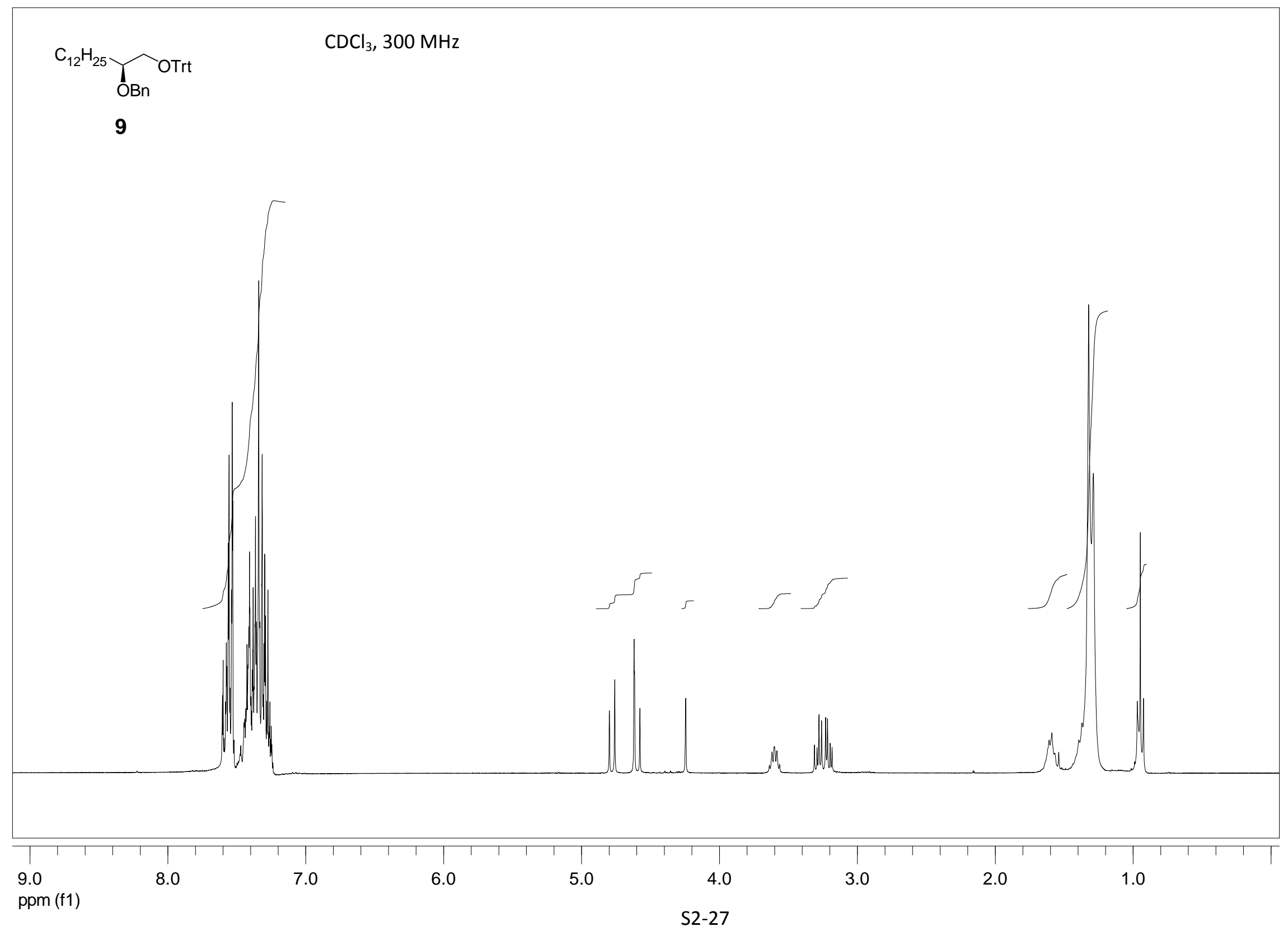




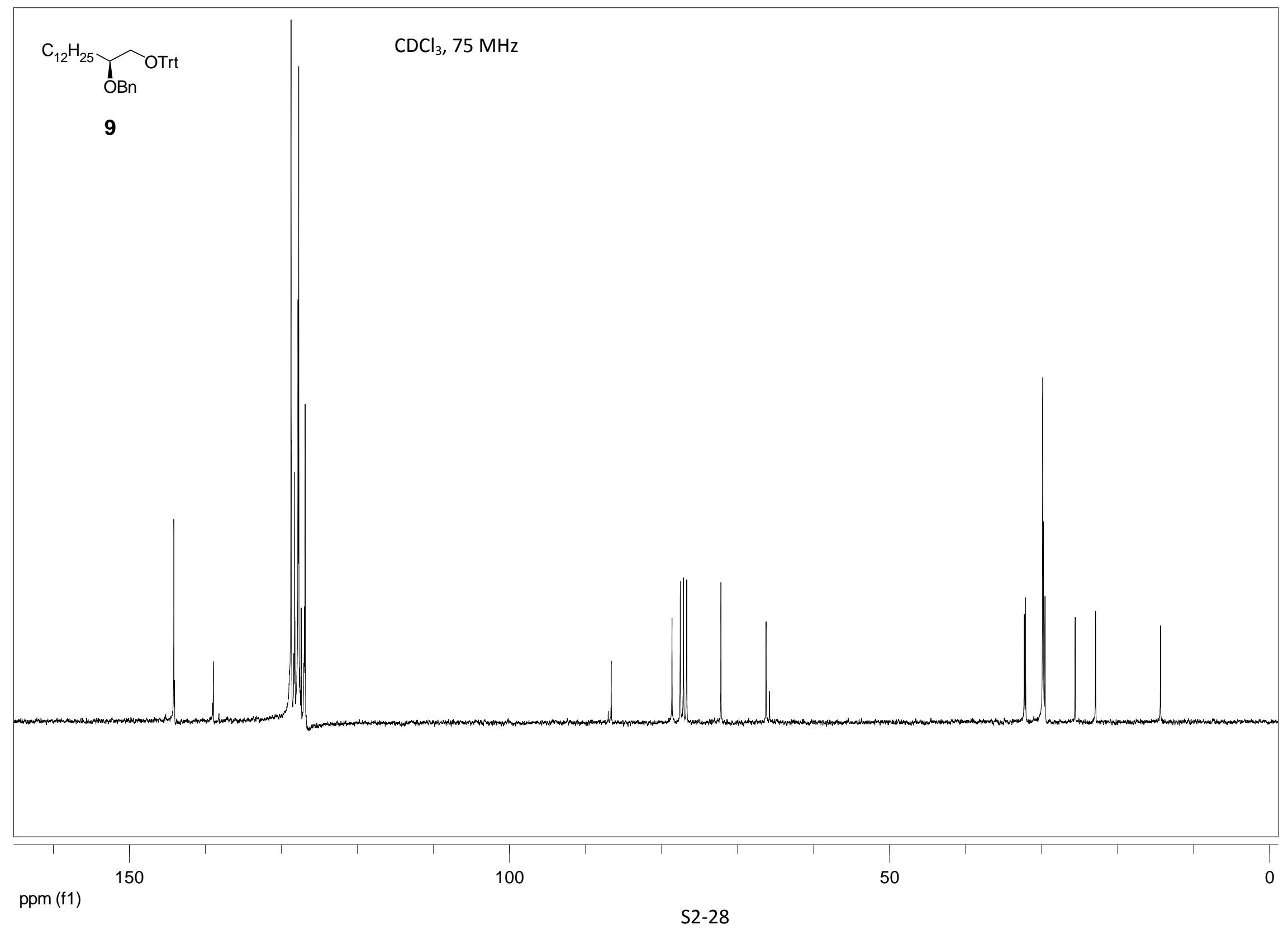




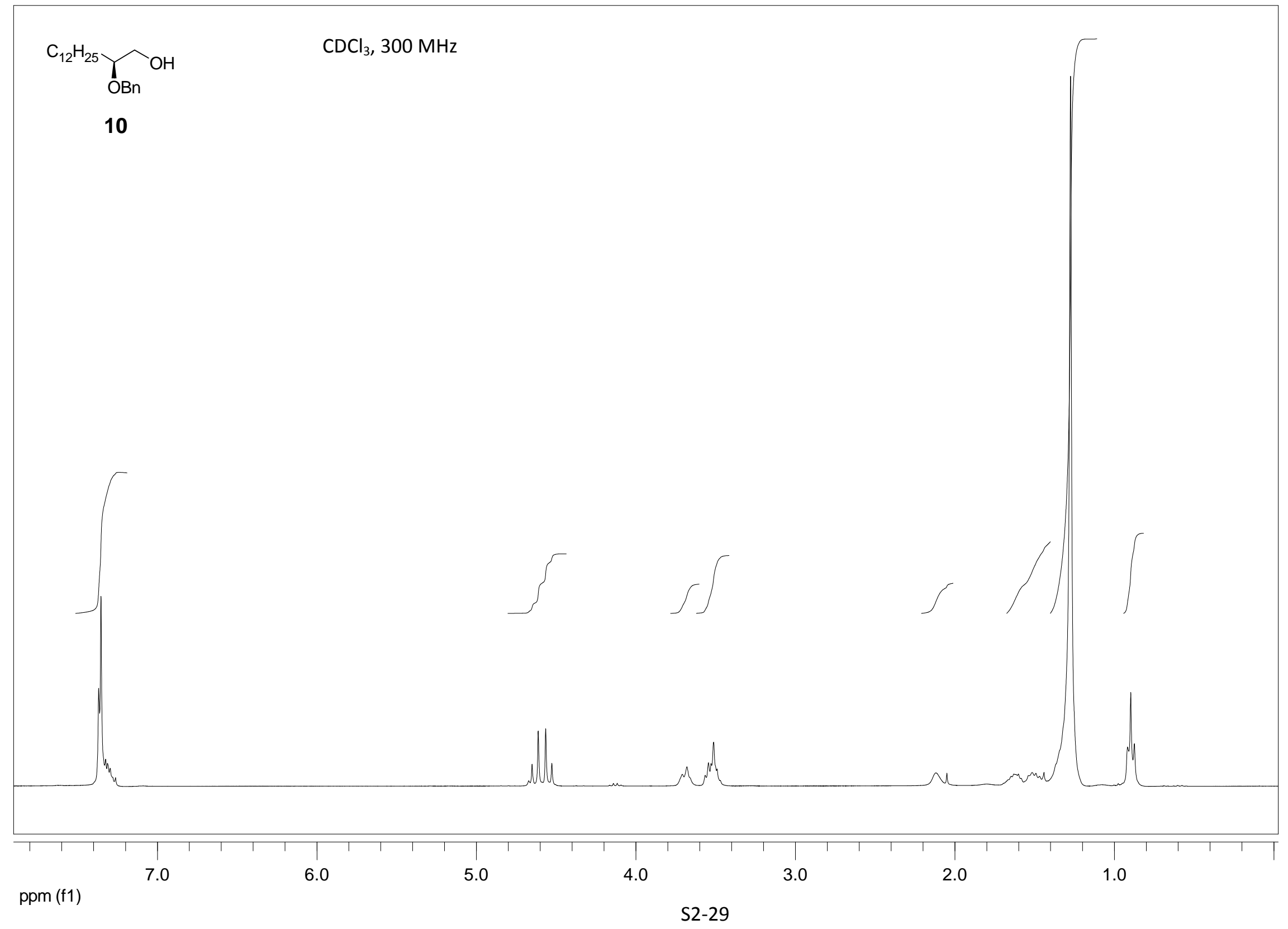




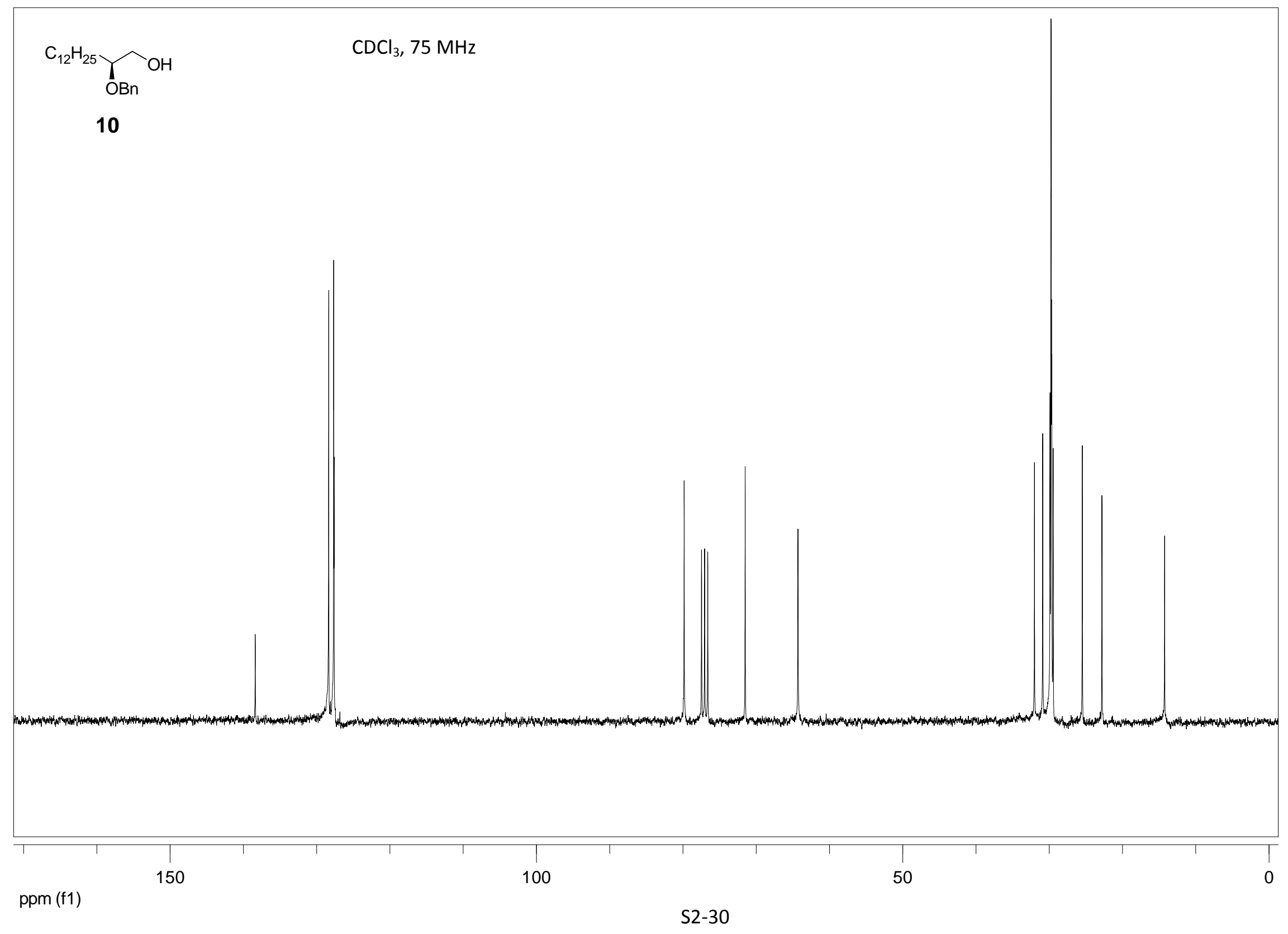




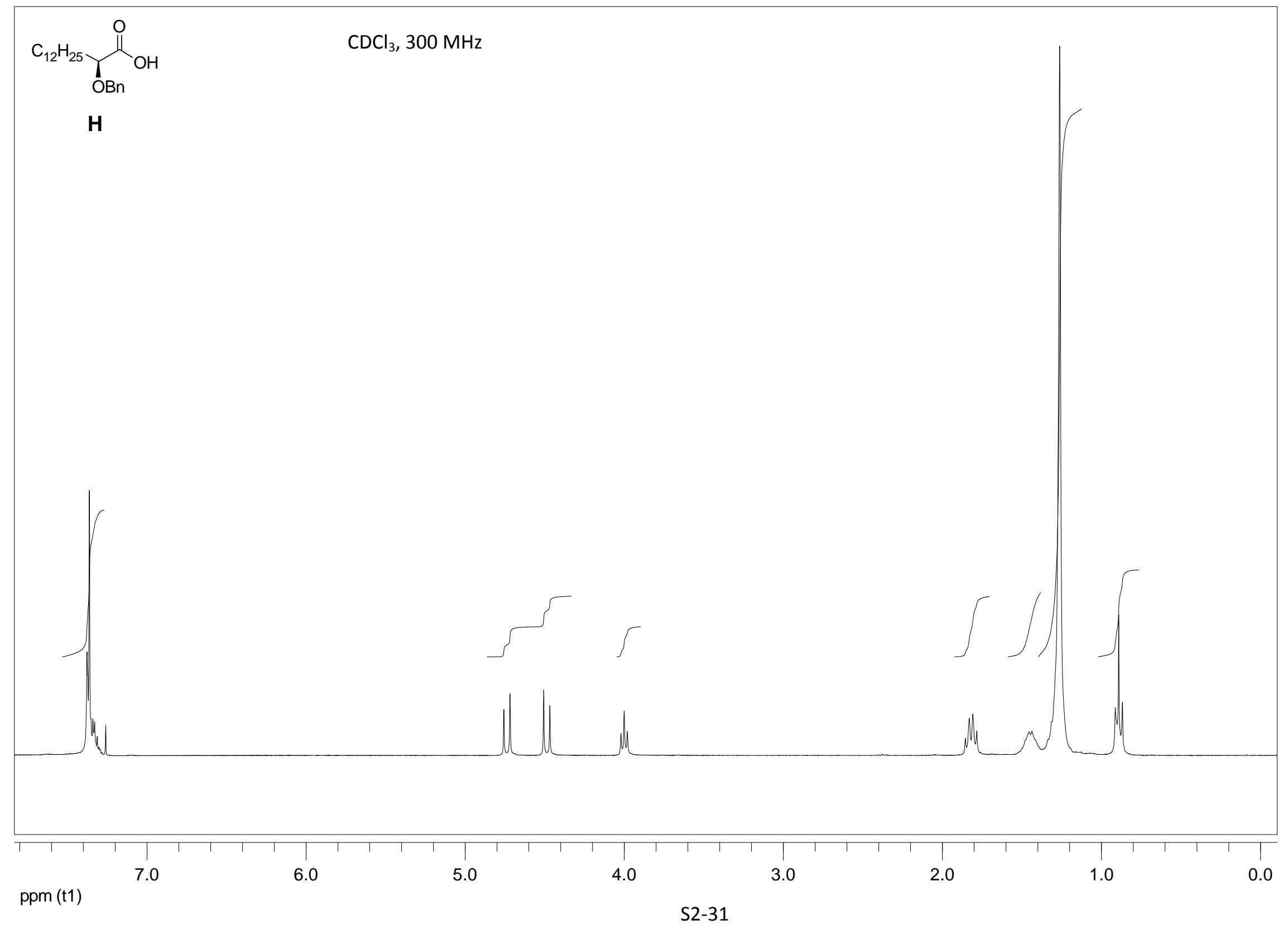




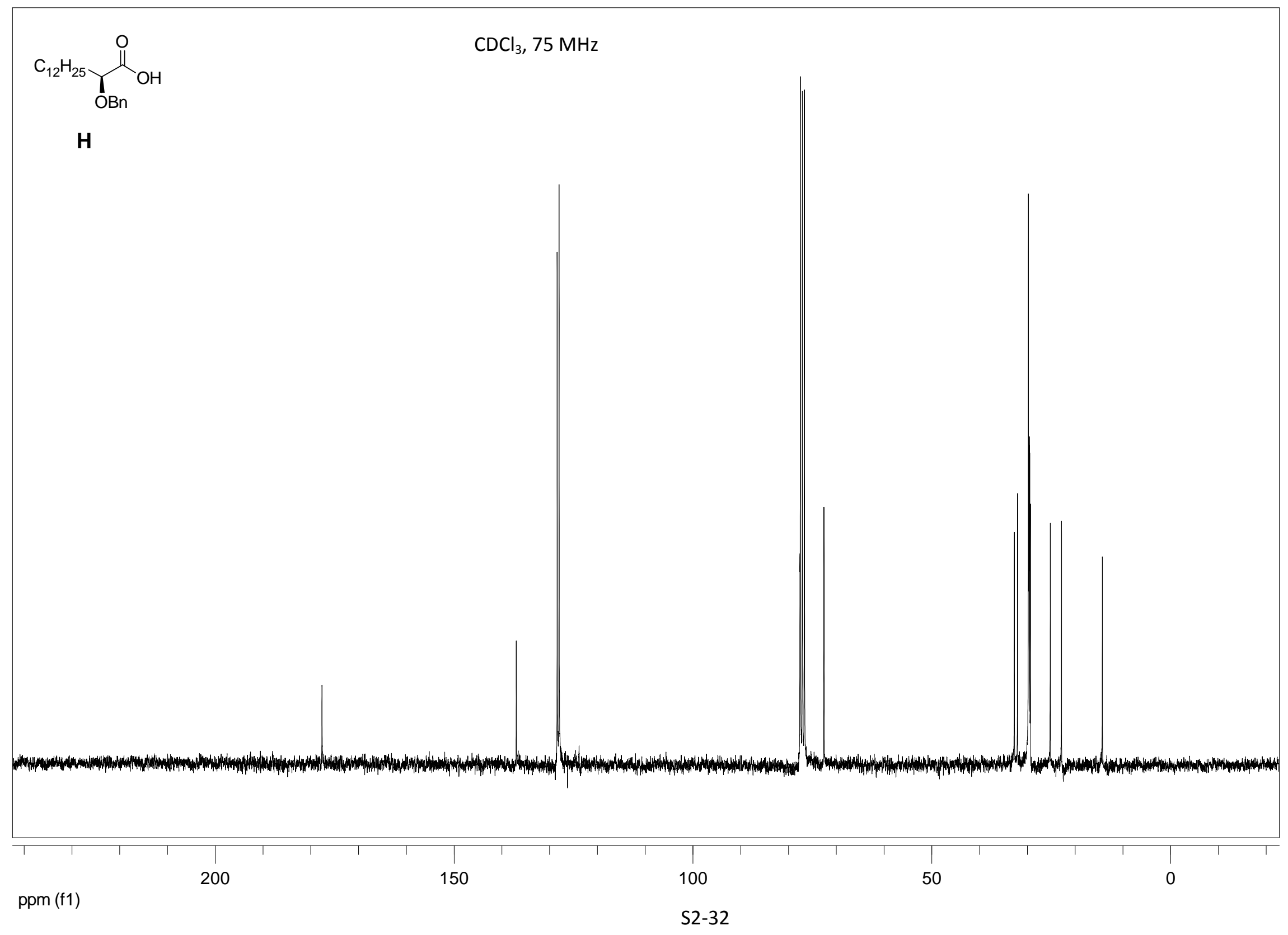




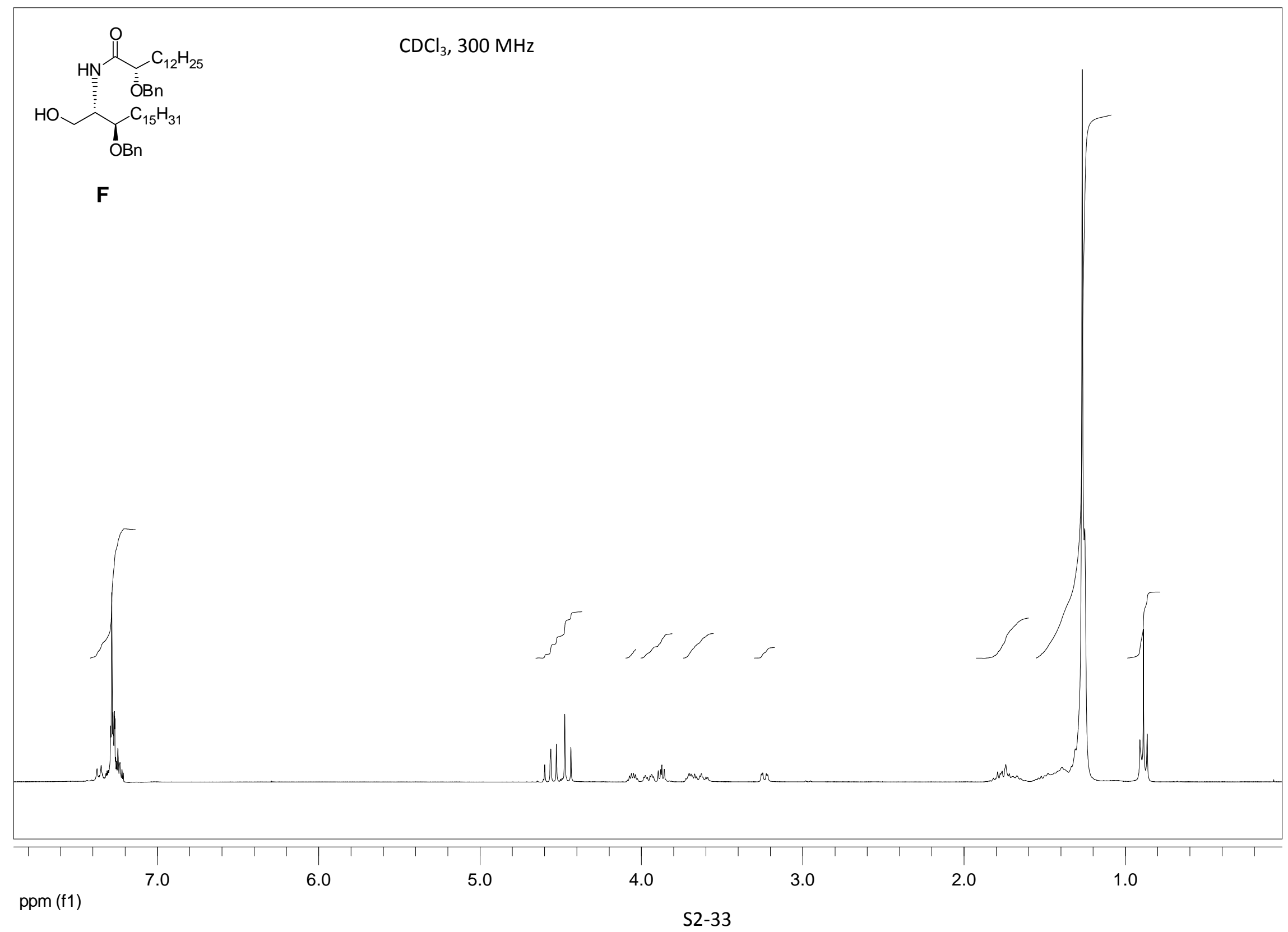




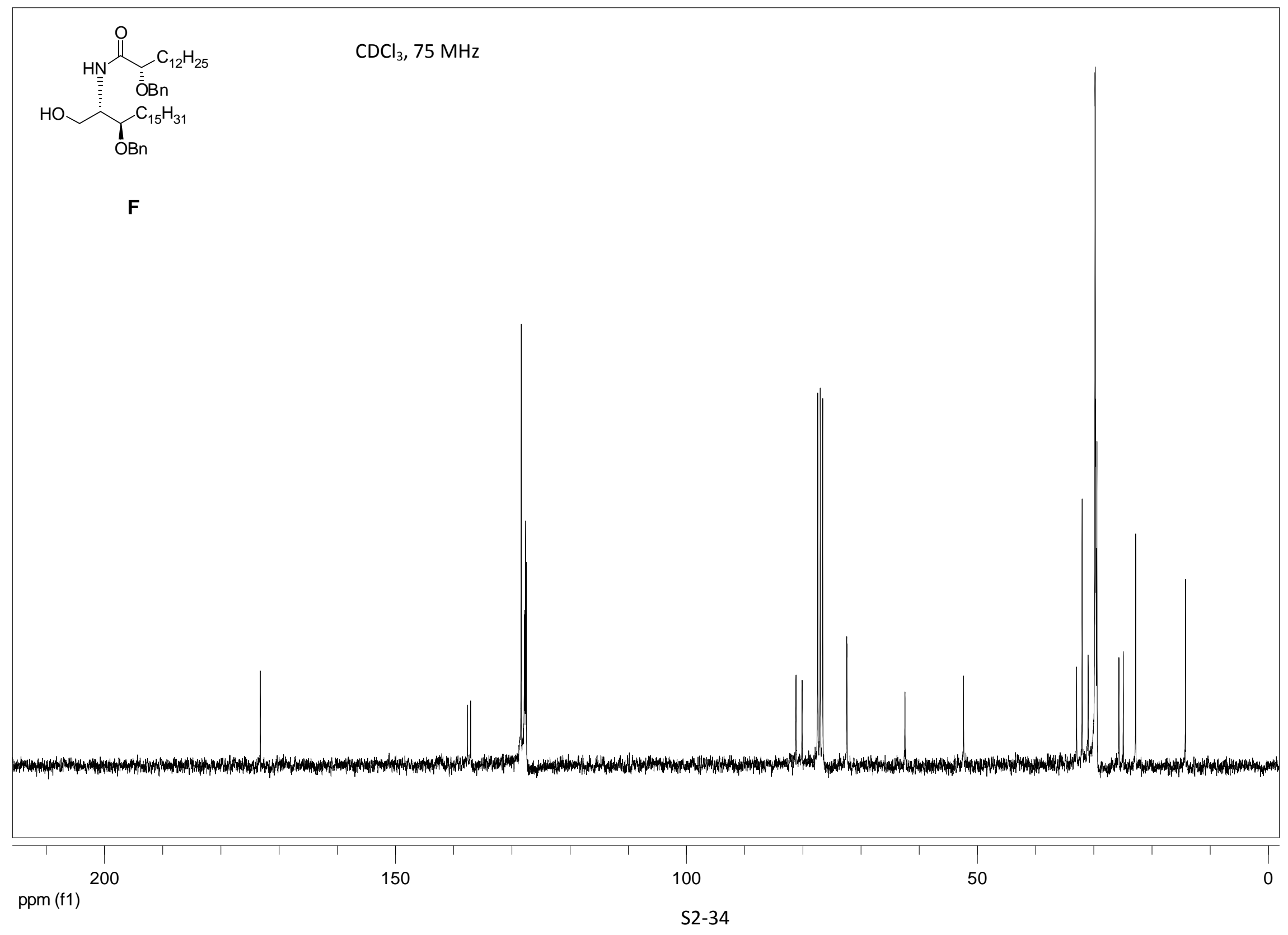




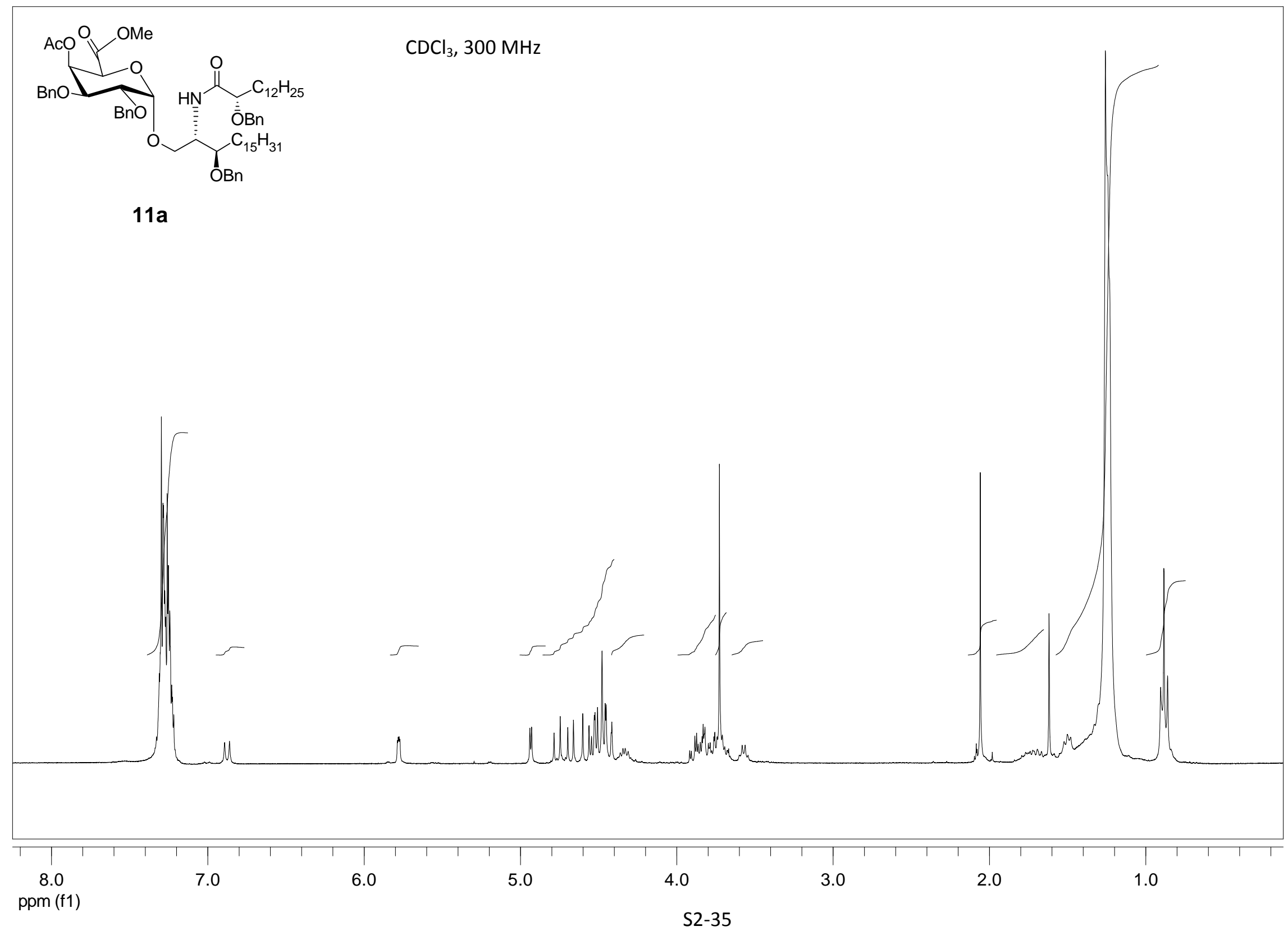




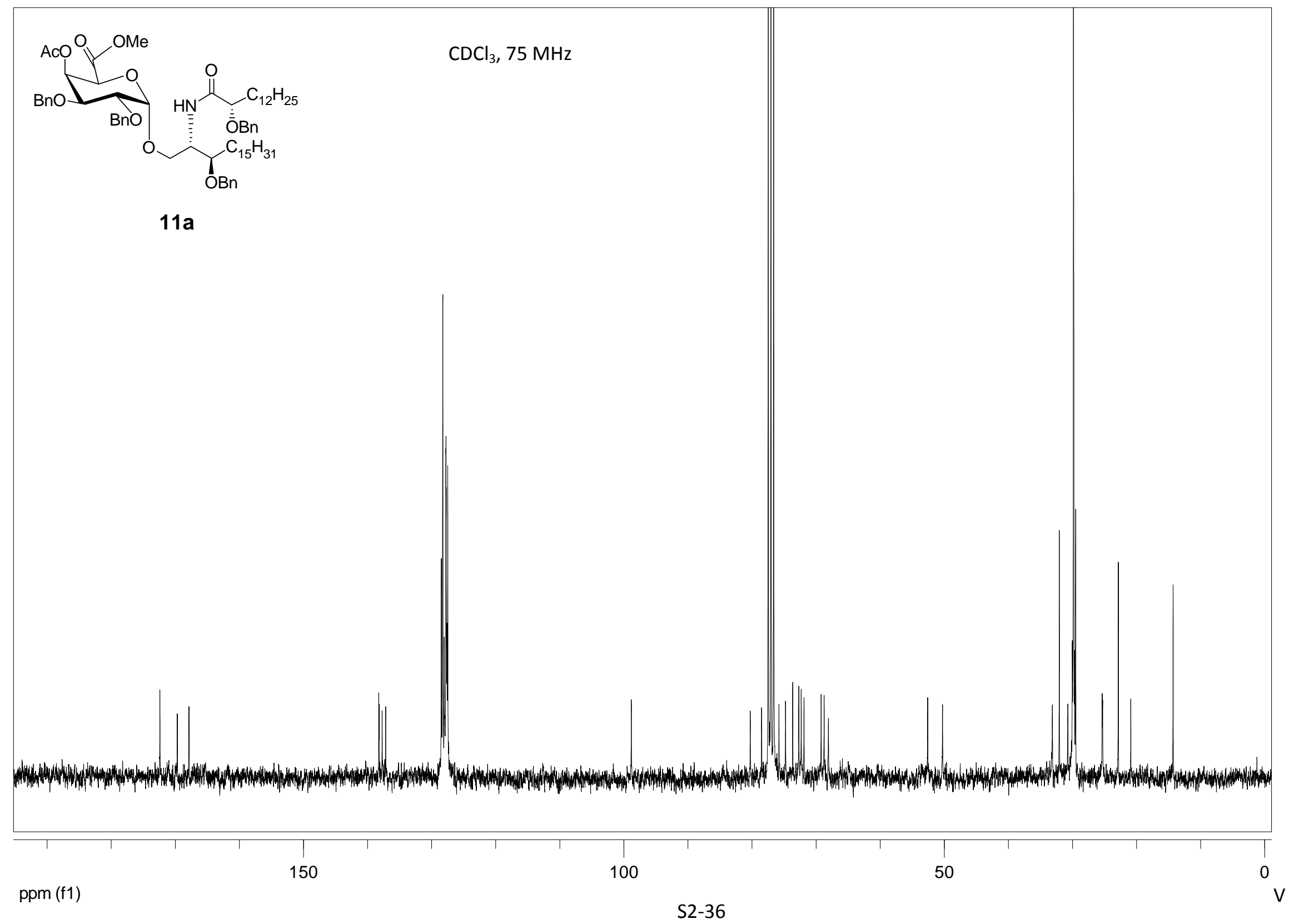




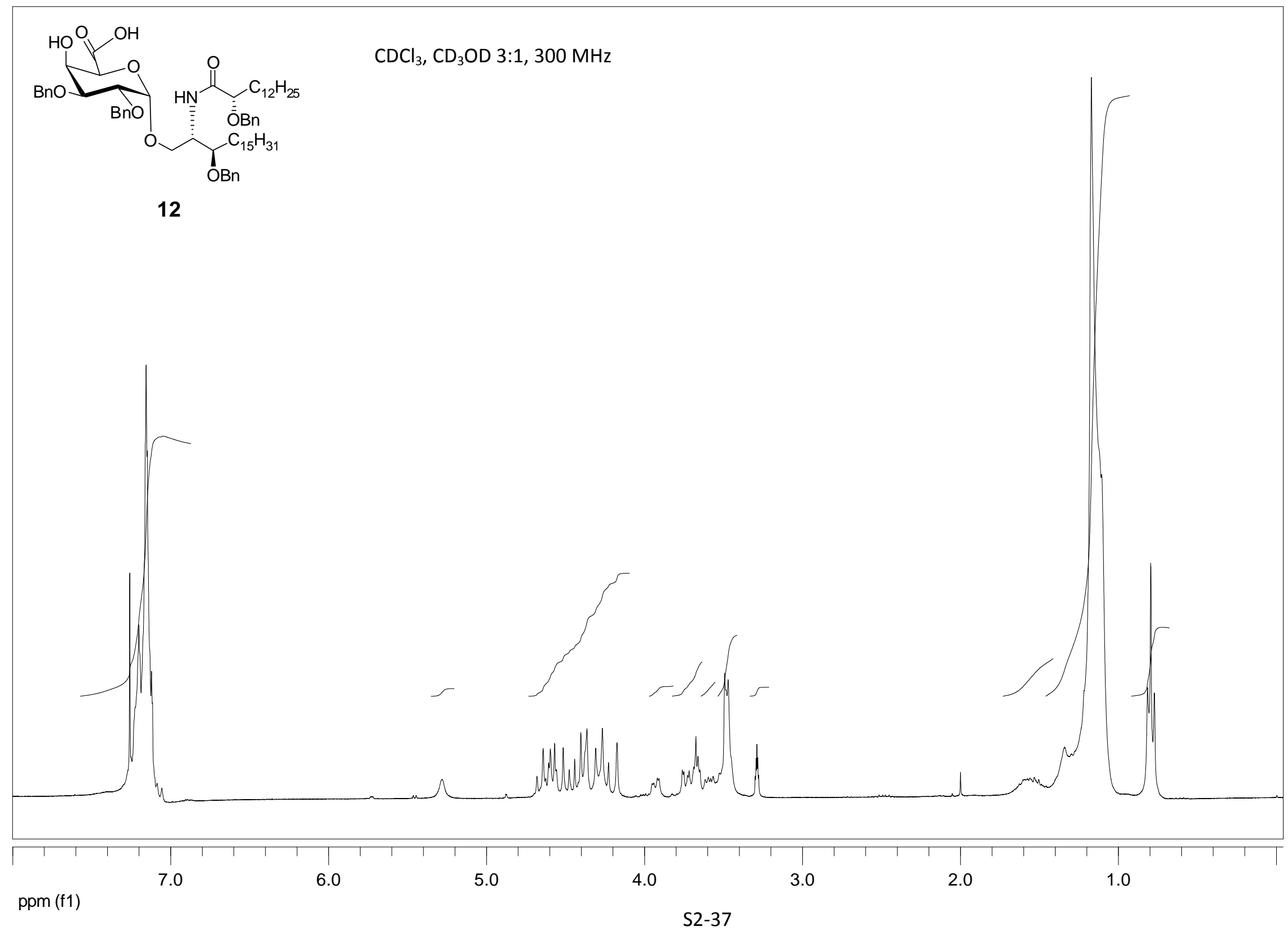




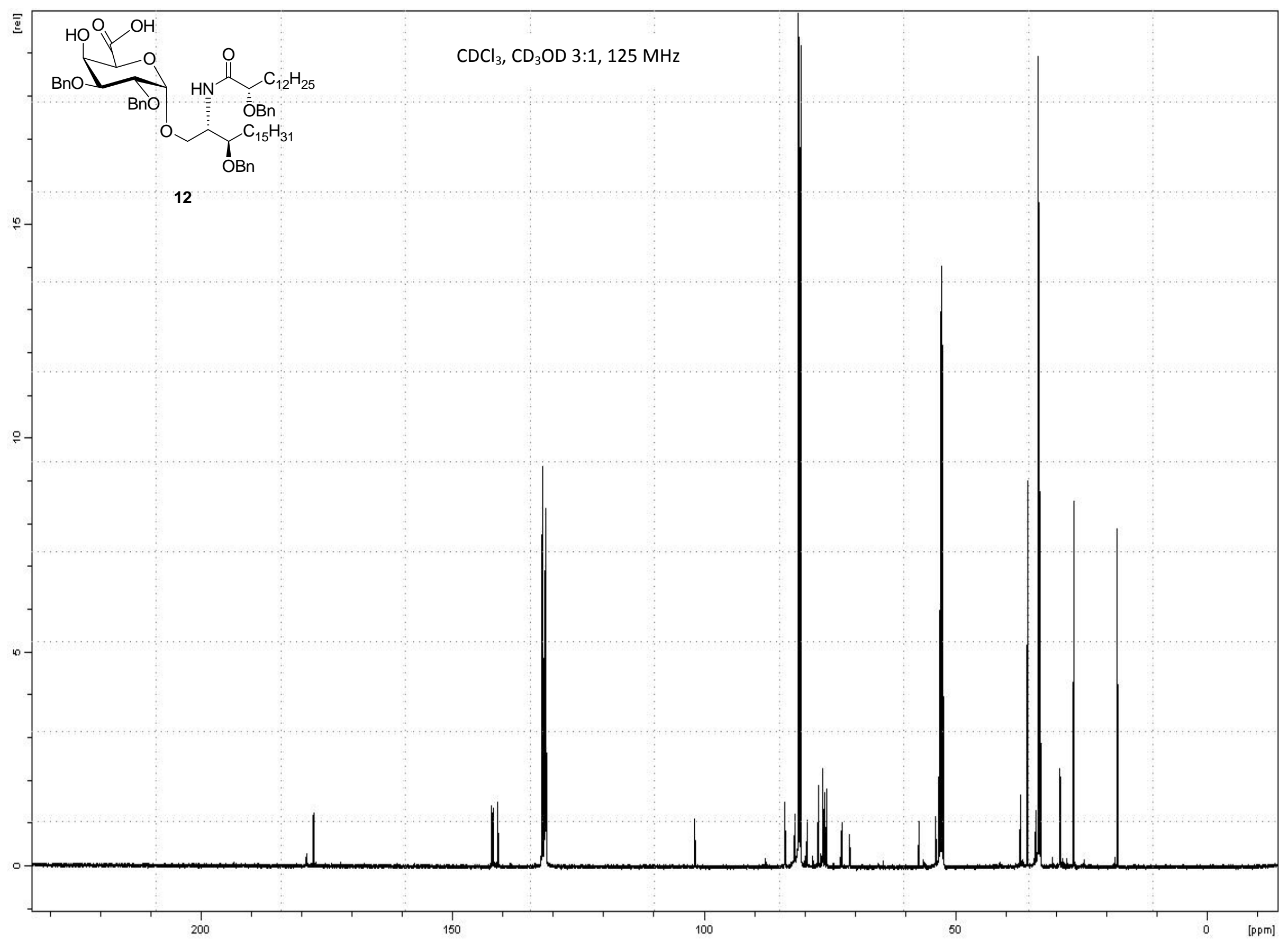




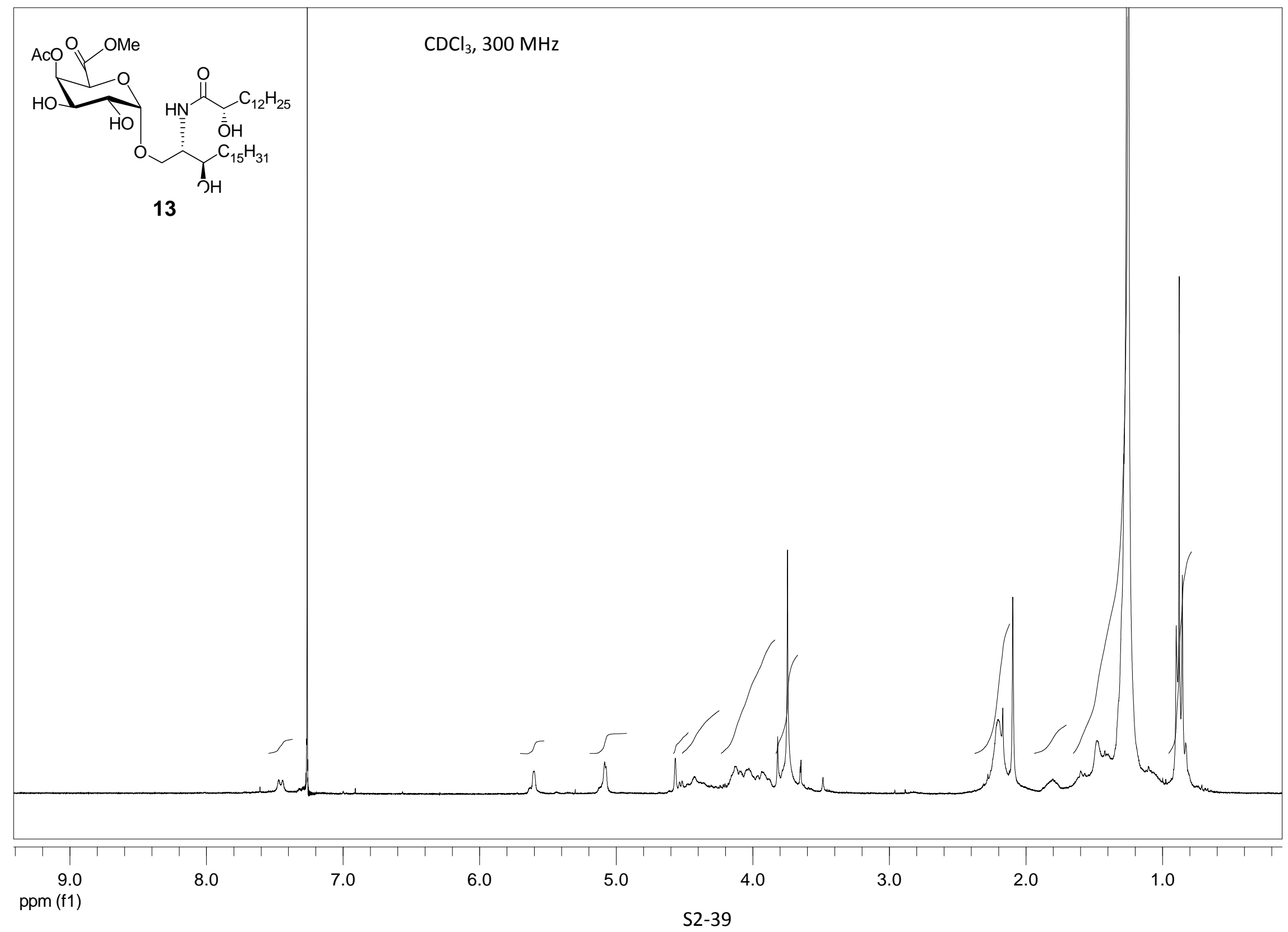




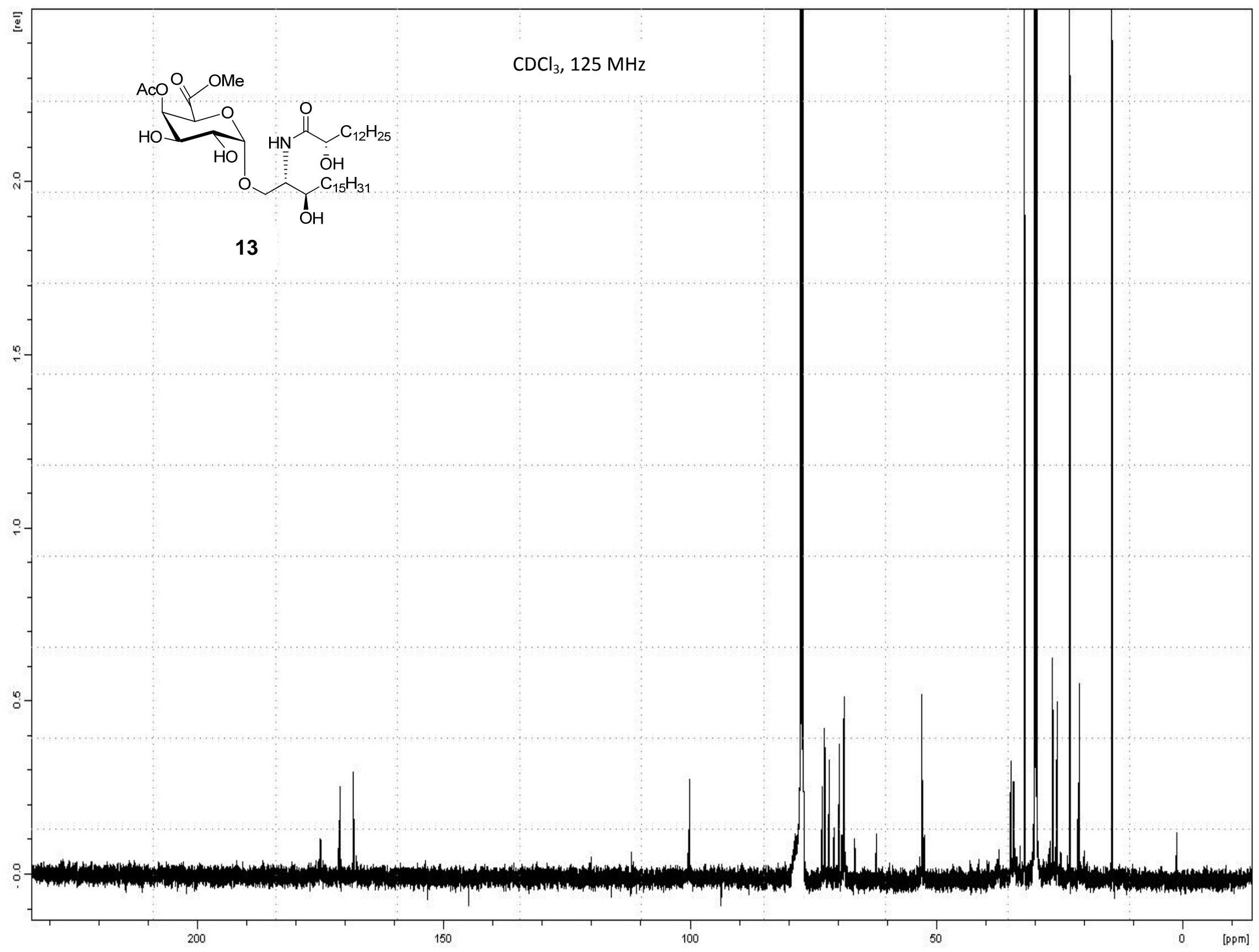

